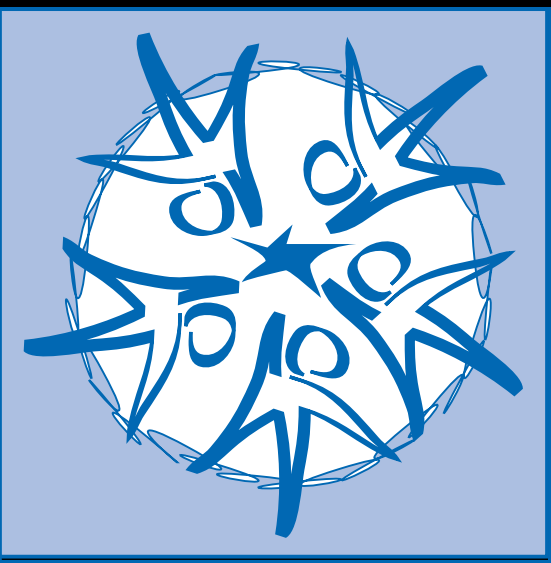

Assessing Safety Net Readiness in Response to Food Price Volatility

Margaret Grosh Colin Andrews Rodrigo Quintana Claudia Rodriguez-Alas

September 2011

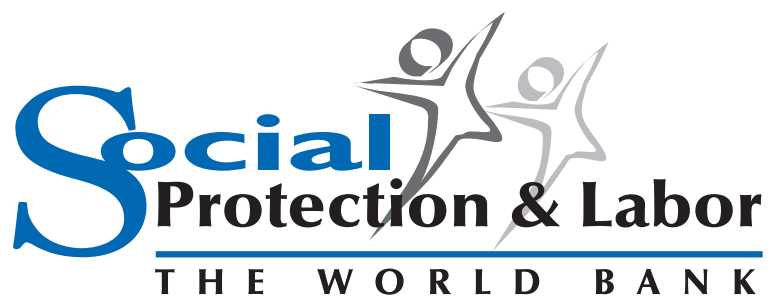




\title{
Assessing Safety Net Readiness in Response to Food Price Volatility $^{1}$
}

\author{
Margaret Grosh \\ Colin Andrews \\ Rodrigo Quintana \\ Claudia Rodriguez-Alas
}

September 2011

\footnotetext{
${ }^{1}$ This paper was drafted at the request of Tamar Manuelyan Atinc by a team comprised of Margaret Grosh, Colin Andrews, Rodrigo Quintana and Claudia Rodríguez-Alas. Helpful suggestions on storyline were made by Harold Alderman, Arup Banerji, Carlo del Ninno, Christian Bodewig, Anna Fruttero, Mamtha Murthi, Helena Ribe, Ludovic Subran, Sophie Warlop, Ruslan Yemtsov and Hassan Zaman, In addition to published materials, the country profiles benefitted from inputs generously provided by country teams: Afghanistan - Oleksiy A. Sluchynskyy; Azerbaijan and Kyrgyz Republic - Anastassia Alexandrova, Alexandra Posarac; Bangladesh - Iffath Sharif; the Democratic Republic of Congo - John Elder; Georgia: Alexandra Posarac, Ramya Sundaram, Vicoria Strokova, Owen Smith; Guatemala - Anna Fruttero, Lucy Bassett; Haiti - Francesca Lamana, David Warren; India - John Blomquist, Puja Dutta and Mansoora Rashid, Indonesia - Jon Jellema and Hassan Noura, Shubham Chaudhuri, Enrique Armas, Vivi Alatas, and Enrique Aldaz-Carroll; Mongolia and Vietnam - Oleksiy Ivaschenko, Tungalag Chuluun; Christian Bodewig, James Adams, Victoria Kwakwa, Robert Taliercio ,Xiaoqing Yu, Coralie Gevers, Valerie Kozel and Deepak Mishra, Pakistan - Cem Mete; Tajikistan Menahem Prywes. All errors are the responsibility of the authors.
} 


\begin{abstract}
In 2008, when food prices rose precipitously to record highs, international attention and local policy in many countries focused on safety nets as part of the response. Now that food prices are high again, the issue of appropriate responses is again on the policy agenda. This note sets out a framework for making quick, qualitative assessments of how well countries' safety nets prepare them for a rapid policy response to rising food prices should the situation warrant. The framework is applied using data from Spring 2011, presenting a snap-shot analysis of what is a dynamically changing situation. Based on this data safety net readiness is assessed in 13 vulnerable countries based on the following criteria: the presence of safety net programs, program coverage, administrative capacity, and to a lesser degree, targeting effectiveness. It is argued that these criteria would remain the same throughout time, even if the sample countries affected would be expected to vary. Based on this analysis the note highlights that though a number of countries are more prepared than they were in 2008 , there is still a significant medium term agenda on safety net preparedness in the face of crisis. In this context, strategic lessons from the 2008 Food Crisis response are presented to better understand the response options and challenges facing governments and policy makers. The note concludes by calling for continued investment and scale up of safety nets to mitigate poverty impacts and help prevent long term setbacks in nutrition and poverty.
\end{abstract}

JEL Classification: H53, I38; Q18, Q02

Keywords: Social Safety Nets, Food Crisis, Price Volatility, Nutrition 


\section{Table of Content}

Page \#

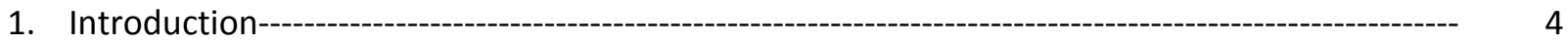

2. Food Price Volatility and the Role of Safety Net: Lessons from 2007/2008------------------- 5

3. A framework for Assessing Safety Net Readiness in Response to Food Crises---- 6

3.1 Criteria for Determining Safety Net Readiness--

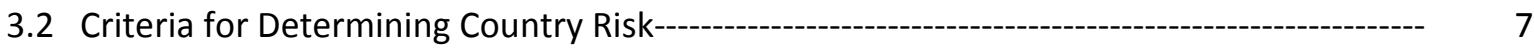

4. Applying the Safety Net Readiness Framework: Case Studies on Food Price Volatility in 20119

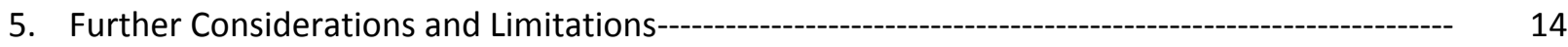

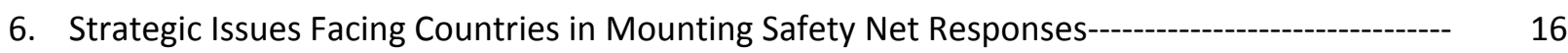

6.1 Determining the most appropriate response - Lessons from previous crises-------------- 16

6.2 Even when there is a strong base for response, there are limitations to achieving full coverage of all those most affected by increased food prices.------------------- 18

6.3 There are strategic questions to face about how to increase benefits or coverage

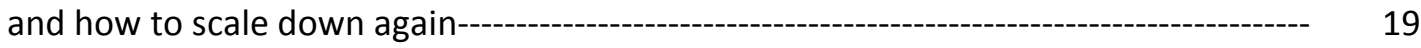

7. The World Bank is Moderately Ready to Help Countries Respond--

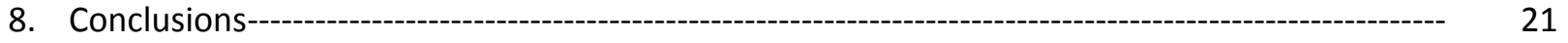

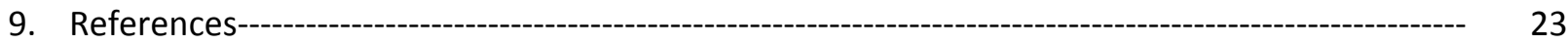

\section{Annexes}

1. Recommendations for Safety Net Policy Response--

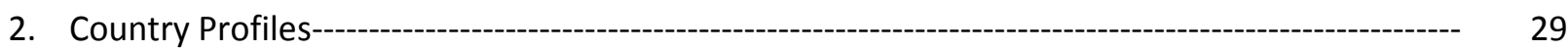

3. Food and Fuel Crisis Response Funding from GFRP, RSR and JSDF Programs 2008-2011-------- 44 


\section{Introduction}

The objective of this paper is to set out a prototype assessment framework for the review of safety net preparedness in response to food price volatility. Through simple, qualitative criteria, the readiness of diverse countries to respond to crisis is presented, taking into account: the presence of safety net programs, program coverage, targeting effectiveness and administrative capacity. The review illustrates the method for 13 countries that, as of spring 2011, were facing significant local food price increases. At the outset of the paper, it is noted that concern relating to food price volatility is obviously broader than the 13 sample countries identified through this analysis. The paper provides a quick snap shot of volatility and response capacity based on data estimates from June-December 2010 estimates. The list may change over time - if world prices stay high, or rise higher, additional countries may see pass through to domestic prices, especially if future local harvests are less robust and countries import more from the international market. Indeed, some months on some amendments are warranted. For instance, the emerging drought situation in the Horn of Africa raises concern in Ethiopia, Kenya and Somalia, and possibly in adjacent countries. In this respect, the real value added of the paper is to provide an analytical framework to better understand the linkages between crisis, safety nets and response. A range of other sources are available to better track and monitor food price levels and the drivers of volatility e.g. World Bank's Food Price Watch, FAO Global Information and Early Warning System (GIEWS).

The paper recognizes the importance of food price volatility and its impacts on human development. As international food prices are again rising precipitously, after high peaks just three years ago, the international policy community is faced with the reality of continued price volatility and the emergence of a medium term agenda for response. While the magnitude of future price volatility is unclear, several factors point to the likelihood of higher real prices and increased volatility going forward e.g. increased bio-fuel demand, increasing oil prices, low food stocks relative to use and changing patterns of food consumption, climate change $(G 20,2011)$. In this respect there is an imperative to better understand how countries are affected, how badly, and how ready are their safety nets.

Prevention and management of price volatility is outside the scope of the social protection sector, but safety nets, if well done, can help limit potential harm from high food prices by:

- Forestalling to a degree the increases in poverty and inequality increased food prices can imply

- Helping households maintain access to food and essential services for health and education

- When perceived as fair and compensatory, social protection programs may help governments avoid 'quick fix' but less efficient tax, subsidy, trade, or production policies, some of which can even aggravate the problem

The analysis builds on the guidance note for Human Development responses to food and fuel price crises, which remains valid (World Bank, 2008 - see annex 1 for the executive summary). The main part of policy response is to provide income support to those most in need. Targeted transfers will be the least cost way of doing so. A range of program options can serve, each with some pros and cons, but a country's response is much more dependent on what it has in place pre-crisis than any technicalities about which program might, in the abstract, be preferable. Nutrition programs may be needed along-side transfer programs, with growth monitoring to detect hotspots, with nutrition education to help households make best use of scarce resources, and with micro-nutrient supplementation programs to help mitigate against lower dietary diversity as a result of changes in food consumption patterns in response to the food price increases. 
The paper proceeds as follows: It starts with a very brief discussion of the price, poverty and nutrition dynamics that motivate an assessment of safety net readiness against food price risks. Next it presents criteria to use in assessing the capacity of a safety net to respond to food price increases. The assessment is then applied through the current 2011 context of food price volatility, through which 13 countries are identified as being at high risk. Then some of the limitations of the assessment framework are presented. The paper moves on to take a brief look at the World Bank's own readiness to support safety net responses. Finally it provides some guidance on strategic choices countries will have to make if they use safety nets as part of a policy response to rising prices.

\section{Food Price Volatility and the Role of Safety Net: Lessons from 2007/2008}

International food prices are spiking again for the second time in three years, igniting concerns about a repeat of the 2008 food price crisis and its consequences for the poor. In March 2011, the food index remained $36 \%$ above its level a year earlier, despite a small recent drop. Key staples that remain significantly higher than what they were at this point last year include maize (74\%), wheat (69\%), soybeans $(36 \%)$ and sugar (21\%); importantly, rice prices have been stable. A comparison of average prices for the first quarter of 2011 with the last quarter of 2010 shows that prices have risen for a broad spectrum of food commodities. Since June 2010, an additional 44 million people fell below the $\$ 1.25$ poverty line as a result of higher food prices. Simulations show that a further $10 \%$ increase in the Food Price Index could lead to 10 million people falling into poverty, and a $30 \%$ increase could increase poverty by 34 million people (World Bank, 2011d).

Rising food prices may negatively affect human development in four dimensions: by increasing poverty; worsening nutrition; reducing the utilization of education and health services; and depleting the productive assets of the poor (World Bank, 2008, Grosh et al, 2008). Disinvestment by the poor in their human and physical capital will have large and lasting effects, which are well documented and quantified in the development literature. Early childhood malnutrition results in poorer health, lower cognitive abilities, less learning, and lower lifetime earnings. Children withdrawn from school in times of hardship rarely return to the classroom, and families can have great difficulty rebuilding the assets upon which their livelihoods are based. Because losses today may be irreversible it is important to see how prevalent the problems are even before a rise in food prices exacerbates them, and how much cushion the population may have before they are forced into these straights.

The people most severely affected by food price shocks are usually poor and vulnerable net food consuming households, on the edge of subsistence and with limited coping strategies. In general the poor have higher shares of food in their consumption basket and sometimes are hungry to start with, so are more affected than the non-poor. Though the poor are concentrated in rural areas, most are probably net consumers of food and so still at risk, at best partially able to mitigate price increases through consumption of own produced food. However, large poor groups such as agricultural laborers are not so protected. Indonesia is a typical example - for every poor household that benefits from higher rice prices, there are three poor households that are net consumers of rice and are harmed by higher prices.

A small body of literature examining the impacts of the 2007/08 Food, Financial and Fuel Crises document the diverse impacts on poor households in poor countries.

- Rising inequality is a disturbing finding, with the rural poor being most affected. Regional inequities have increased, e.g. rural regions which are in food deficit are likely to have become poorer with a 
high proportion of the 'new poor' coming from urban areas thus raising classic political economy dilemmas regarding best use of resources (Compton et al. 2010).

- The limited evidence available supports predictions that nutrition would suffer when food prices rose. At the height of the 2008 crisis, poor families most frequently responded to higher food prices by eating cheaper foods with lower nutritional value, consuming less food in meals and skipping meals (Brinkman et al. 2010 and Compton et al. 2010). Such behavioural changes can cause micronutrient deficiencies even when caloric intake is sufficient, and more extreme deprivation can ultimately lead to weight loss and severe malnutrition (Skoufias, Tiwari and Zaman, 2011; D'Souza and Joliffe. 2011). The most notable difference from previous economic crises was that there was no evidence of weight decline (on average) in women, although micronutrient malnutrition was likely.

- Similarly, large numbers of children were removed from school in some locations when food prices rose, or parents cut back on other expenses to keep children in school. Understanding what factors help keep children in school during a food crisis (e.g. flexible schooling and payment systems, social transfers and or school feeding) is important and requires more analysis (Compton et al. 2010).

- Behavioral surveys indicated that increased indebtedness may be a problem. Buying food on credit - or getting credit in cash to buy food - featured as one of the two most widely reported livelihood responses. In Cambodia, more than a third of households indicated 'buying food' as their first $(20 \%)$ or second (38\%) reason for contracting the most recent loan (Ortiz et al, 2011).

\section{A Framework for Assessing Safety Net Readiness in Response to Food Crises}

In this section we present a framework on how safety net readiness can be assessed in response to food price crises. An important introductory caveat stresses that the assessment framework applies to food crises. It does not give a balanced view of a country's safety net policies more broadly. It looks only at one of the problems that a safety net might be called on to solve, ignores issues of incentive-compatibility and underplays those of dynamism and sustainability, criteria that are important in more balanced or longer term assessments. (or a more comprehensive discussion of safety nets and their assessment, see Grosh et al, 2008).

$\mathrm{F}$

In this section we consider the criteria for better determining safety net readiness and food price volatility. Some of the considerations and limitations around these criteria are discussed in Section 5, in particular the time sensitivity of the sample and the fact that concern of food price volatility is obviously broader than the sample emerging at a specific point in time below.

\subsection{Criteria for Determining Safety Net Readiness}

The simple, qualitative criteria we use to judge food crisis readiness is whether a country operates one or more high coverage or scalable poverty targeted programs with sound administrative systems that might be used as safety net response $\mathbf{2}^{2}$. There are many gradations of readiness by these criteria or the subelements of it. Moreover, there are qualitative judgments involved in such a classification, especially in terms of the quality of administration systems and their flexibility. A few words of explanation:

- Presence of Safety Net Interventions Appropriate to the Issue of Rising Food Prices: This is a key criterion. Since safety net programs take time to develop, a response that must wait for a new program to get to scale will surely allow harm to be done in the meantime. Some existing

\footnotetext{
${ }^{2}$ For a further discussion on the attributes of a good safety net systems refer to Grosh et al (2008).
} 
programs that are fine and logical parts of the overall safety net system - e.g. fee waivers for health care - will be less apt for response to this particular problem than say poverty-targeted cash transfers or school feeding in poor rural districts.

- Program Coverage: While small programs may provide very good impacts for their clients, the problem of increased food prices will be felt widely across the poor in both rural and urban areas. A high coverage of such programs will be needed to prevent the suffering and losses to human capital and livelihood that can result from further immiserization.

- Administrative Capacity: Well functioning institutional mechanisms and administration are critical in order to scale up and down interventions at short notice, and to ensure transfers reach intended beneficiaries at the right time and place. Components of good program administration include:

- Outreach effort to ensure those who might be eligible know about program, its benefits, and how to apply quickly;

- Eligibility criteria that are technically sound, publicly known and viewed as fair;

- Payment system that delivers the right payment to the right persons at the right time, with low transactions costs to both recipient and program;

- Management information system that provides adequate basis for timely program operations and provides fiduciary safeguards;

- Grievance and redress system to correct individual-specific transaction errors in program processes;

- Monitoring and evaluation system that provides information on processes and impacts so that program can be continuously improved in execution and periodically in design if needed;

- Communications strategy to communicate purpose, procedures and outcomes in a transparent way to different groups - clients, staff, the general public and those who provide funding - and ensure political buy-in during crisis settings.

- Targeting Mechanisms: Countries legitimately choose to have different balances between universal or broad based programs and narrowly targeted ones, and thus the weight of these criteria in a crisis response assessment is somewhat debatable, and it should probably be less than for the first three criteria mentioned. The use of universal programs (e.g. child allowances) for crisis response is quite expensive relative to more targeted options. And as it may be difficult to scale down universal benefits after a food price spike the tradeoffs between adequacy and sustainability may become particularly acute. Additionally, categorically targeted programs are not fully suitable as response vehicles either, as there are many poor who are not part of the supported groups (which commonly include the disabled, often the elderly, and sometimes widows). Thus the ability to identify and reach poor populations through targeted assistance can be helpful in crisis response, particularly in light of resource constraints. Established targeting mechanisms can also provide policy makers with a transparent and accountable approach to justify policy choices.

\subsection{Criteria for Determining Country Risk}

What matters most directly to household welfare is local domestic prices and thus we look at these to see which countries are most at risk $^{3}$. Depending on data availability and local consumption patterns, following the trends in the prices of locally important staples and of overall food price inflation can give indicators of distress. In the analysis that follows, we focus on two criteria (i) price increases in staple foods

\footnotetext{
${ }^{3}$ Rising prices are due to higher international prices for cereals and oil, booming domestic demand and a range of local factors. The impact of global price rises on local prices, and on poor people, has varied hugely and has also been shaped by the legacy of the 2007/08 food price crisis. Even after the moderation of the previous food crisis, local price spikes of key staples continue to affect some countries with already high levels of poverty and malnutrition (e.g. Afghanistan, Pakistan). For further discussion refer to World Bank, 2011a.
} 
greater than $5 \%$ from June to December 2010 , for staples constituting more than $20 \%$ of diet and (ii) where local food price inflation has been particularly acute.

Using these criteria and time period, we identify 13 countries that in spring 2011 were facing particularly high local price increases. 10 (Afghanistan, Azerbaijan, Bangladesh, the Democratic Republic of Congo, Guatemala, Indonesia, the Kyrgyz Republic, Mongolia, Pakistan, and Tajikistan) have risk signaled by increases greater than $5 \%$ in local prices of staples with a share in local diets of more than $20 \%$ (from the most recent Food Price Watch, Feb 2011). We also consider 3 countries with high overall year on year food price inflation: This includes Georgia (24.8\%), India (18.3\%), and Haiti (7.8\%) (see Table 1). Food price volatility persists in the majority of these countries. High prices have stabilized at plus/minus $5 \%$ of their spring level in Afghanistan, Bangladesh, DRC, Indonesia and Mongolia but they continued to climb almost 817\%higher than December 2010 levels in Azerbaijan, Guatemala, Kyrgyz Republic, Tajikistan and Pakistan.

No attempt is made here to define extreme or excessive price volatility. Suffice it to say that volatility becomes an issue for concern and for possible policy response when it induces risk averse behavior that leads to inefficient investment decisions and when it creates problems that are beyond the capacity of producers, consumers or nations to cope. What constitutes excessive volatility depends very much on the situation of the individual or nation (G20, 2011).

Table 1. Countries Facing High Food Price Increases in Spring 2011

\begin{tabular}{|l|c|c|c|c|}
\hline \multicolumn{5}{|l|}{$\begin{array}{l}\text { with Increase in Domestic Staple Price Greater than 5\% June - Dec. } 2010 \\
\text { and Calorie Share for Staple Greater than 20\% }\end{array}$} \\
\hline COUNTRY & STAPLE & PRICE INDEX & $\begin{array}{c}\text { CHANGE IN } \\
\text { PRICE (\%) }\end{array}$ & $\begin{array}{c}\text { CALORIE } \\
\text { SHARE (\%) }\end{array}$ \\
\hline Afghanistan & Wheat & Retail, Kabul & 19 & .. \\
\hline Azerbaijan & Wheat & Retail Nat. Average & 24 & 57 \\
\hline Bangladesh & Rice & Retail, Dhaka & 19 & 70 \\
\hline Congo, DR & Cassava & Retail, Kinshasa & 20 & 53 \\
\hline Guatemala & Maize & Retail, Nat. Average & 8 & 40 \\
\hline Indonesia (Average) & Rice & Retail, Nat. & 19 & 50 \\
\hline Kyrgyz Republic & Wheat & Retail, Bishtek & 54 & 40 \\
\hline Mongolia & Wheat & Retail, Ulaanbaatar & 33 & 42 \\
\hline Pakistan & Wheat & Retail, Lahore & 16 & 37 \\
\hline Tajikistan & Wheat & Retail, Nat. Average & 37 & 54 \\
\hline \multicolumn{7}{|c|}{ Countries with High Food Price Inflation 2011: Year on Year } \\
\hline
\end{tabular}

\footnotetext{
${ }^{4}$ While Vietnam was initially featured in the Food Price Watch data, subsequent data revisions prompted its removal from the analysis. To this end, Vietnam is not featured as a country within the assessment.
} 


\begin{tabular}{|l|l|}
\hline Georgia & 24.8 \\
\hline Haiti & 7.8 \\
\hline India & 18.3 \\
\hline
\end{tabular}

Source: World Bank Food Price Watch, February 2011, based on FAO, GIEWS.

${ }^{\dagger}$ Georgia: National Statistic Office of Georgia, February 2011. Haiti: Country Team. India: World Bank, 2011a.

Of course, it should be noted that alternate criteria for the watch list would yield a different set of countries, and though the way in which we would assess the readiness of safety nets would be similar, the share of countries in the different categories may change somewhat. If we lower to $10 \%$ the share of calories coming from a single staple with a price increase, then Brazil (wheat), Bolivia (wheat), Burundi (beans), Peru (maize), Sri Lanka (wheat), Sudan (wheat) would enter the watch list. If countries with modest increases in the prices of multiple staples were included, then Burundi would be on the list. If historical patterns of seasonal prices are discounted, then the DRC might be removed from the list.

\section{Applying the Safety Net Readiness Framework: Case Studies on Food Price Volatility in 2011}

The response preparedness of their safety nets varies strongly across the most affected countries facing food price volatility. We find a strong basis for response in 1 country; a moderate base in 8 countries; a weak base in 1 country and 3 countries to be unprepared (see Annex 2 for country specific information ${ }^{5}$ ).

Table 2: Crisis Response Preparedness across Countries Currently Flagged as Greatly Affected by Food Price Changes

\begin{tabular}{|c|c|c|}
\hline Basis for Response & Criteria & Countries $^{+}$ \\
\hline Strong & $\begin{array}{l}\text { Have one or more programs with high } \\
\text { coverage of poor, highly progressive } \\
\text { targeting and good administration }\end{array}$ & Georgia $^{*}$ \\
\hline Moderate & $\begin{array}{l}\text { Have one or more operating and } \\
\text { progressively targeted programs to } \\
\text { build on, but with less than full coverage } \\
\text { and /or a need for administrative } \\
\text { improvements }\end{array}$ & $\begin{array}{l}\text { Azerbaijan, Bangladesh, } \\
\text { Guatemala, India* Indonesia, } \\
\text { Kyrgyz Republic, Pakistan, } \\
\text { Mongolia }\end{array}$ \\
\hline Weak & $\begin{array}{l}\text { A large scale response would require } \\
\text { fundamental changes to range, size, or } \\
\text { targeting of programs and significant } \\
\text { building of institutional capacity }\end{array}$ & Tajikistan, \\
\hline Unprepared & $\begin{array}{l}\text { Very small programs with little } \\
\text { institutional development, often geared } \\
\text { only to specific sub-groups of the } \\
\text { population }\end{array}$ & Afghanistan, DRC, Haiti \\
\hline
\end{tabular}

${ }^{\dagger}$ Currently Facing Large Increases in Domestic Prices of Important Staples. Based on Food Price Watch 2011 data, see Box 2011. Inclusion based on overall food price inflation

Source: authors' compilation

\footnotetext{
${ }^{5}$ Country information is drawn from the sources listed in the appendix and correspondence with the World Bank country teams working with each country.
} 
Some general features of the assessment indicate that:

- The currently most affected countries are poor on multiple dimensions and their poor are likely to be at risk of loss of human capital or losses to livelihood in the face of increased food prices. Poverty rates are high, and the estimated share of food consumption in expenditure is high - in the range of $60-70 \%$ for extremely poor households living under $\$ 1.25$ per day (See Figure 1 ), and much lower in some countries than for the non-poor. For example, in Guatemala, those in the poorest decile devote $56 \%$ of their resources to food; those in the top decile $15 \% .10$ of 13 are on the list of concern to the nutrition sector - having either large numbers of malnourished children or rates of malnutrition greater than $20 \%$. Because they start from low bases, these populations can afford little additional hardship without risk of long term consequences.

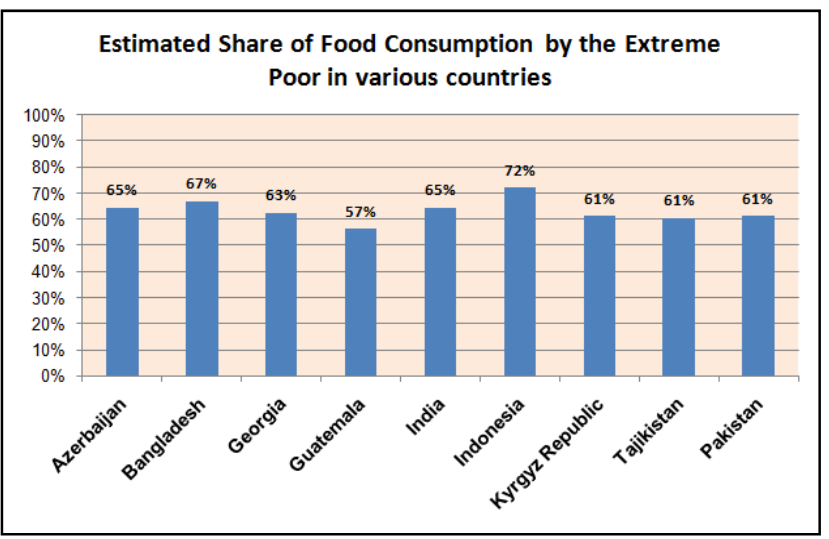

Source: De Hoyos and Lessem, 2008

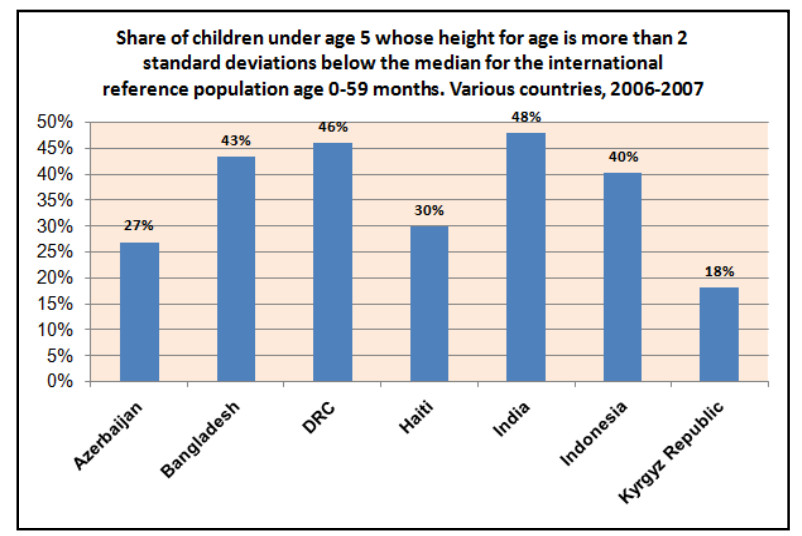

Source: World Development Indicators

- 12 of the 13 identified countries are eligible for World Bank IDA assistance, and 4 are fragile states. This highlights the vulnerability in particular of low income countries to food price shocks, as well as the food and nutrition concerns of concern. As highlighted in Section 1, behind concerns about volatility lie concerns about price levels, and behind both lie concerns about food security (g20, 2011).

- Response capacity is constrained by fiscal deficits, mirrored also be reduced availability of donor aid. In the 13 countries examined in depth, 11 had deficits, and they were particularly high in the DRC $(12.7 \%)$, with others in the region of $3-4 \%$ of GDP. Some countries are less constrained. Indonesia, for example, has small surplus (0.6) and public debt (26\% of GDP) and could afford to respond by ramping up existing initiatives (see Annex 2). Prudent deficit finance is an inherent part of counter-cyclical safety net policy and many countries used it in the $2008 / 9$ crisis years, but there are limits and some of these countries appear to have reached them.

- Several of the 13 countries most at risk in are more prepared in 2011 than they were in 2008. 5 rolled out new programs in 2008/9 that may serve as the basis of response now. Bangladesh reactivated its 'open market' subsidized rice sales in urban areas and developed its 100 Days Employment Program. Guatemala has developed its conditional cash transfer (CCT) program, Mi Familia Progresa. Indonesia reactivated a temporary unconditional cash transfer (UCT) program, the Bantuan Langusng Tunai, Mongolia created its food stamps program, Pakistan rolled out its UCT program, the Benazir Income Support Program. 4 other countries on the watch list have received World Bank crisis-related funding, all of which include a technical capacity component to support safety net strengthening (Kyrgyz Republic, Tajikistan, Haiti and the DRC). We proceed to 
examine the safety nets in all 13 countries, as a means of getting a sense of where we stand globally and of demonstrating criteria that might be used in such assessments by country teams for any country of concern.

- The level of preparedness of the low income countries in this sample is probably better than the average for low income countries. At the time of the initial price analysis, rice prices had not risen as fast as other grains, so the small Asian countries with limited safety nets were not on the watch list. More visibly, African maize and millet harvests had been good, limiting domestic price increases and thus leaving most African countries off the watch list. However, most of sub-Saharan African countries have only nascent safety net systems, though there are many cash transfer programs on the continent, most are very small scale, often short term, and lacking robust systems for registry and accountability. In recent weeks, drought in the Horn of Africa has underscored dramatically the lack of safety nets in a number of countries - in Somalia and Sudan the only response vehicles are emergency humanitarian assistance, even in Ethiopia with the large scale Productive Safety Net Program, the extent of crop failure and need is challenging the system.

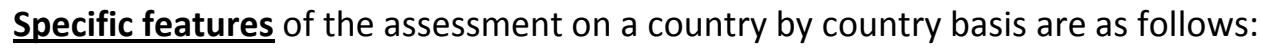

Georgia has a strong basis for response in its nationally Targeted Social Assistance (TSA) program. Though first introduced as recently as 2006, it has become Georgia's most important social assistance program in terms of resources (cost $0.8 \%$ of GDP in 2010) and poverty impact reaching about 400,000 people ( $10 \%$ of the population). Importantly it has an automated management information system/unified beneficiary registry comprising a database of poor and vulnerable people containing $40 \%$ of households in Georgia, which is also used to target other programs such as medical insurance. Moreover, the TSA program responded well to the triple wave of Finance, Food and Fuel crises increasing its beneficiaries robustly through 2009. The Government is planning to take steps to further improve TSA administration processes through integrated IT systems with a focus on a client-friendly, one-stop shop approach to operating local State Social Service Agency offices.

Countries with a moderate base have transfer programs with progressive targeting and good design elements, yet low program coverage. Azerbaijan and the Kyrgyz Republic have poverty targeted cash benefit programs not unlike those in many countries in Eastern Europe and Central Asia. They have good targeting though somewhat low coverage and/or benefits and static rosters - a quarter of the poorest quintile in the Kyrgyz Republic, a sixth in Azerbaijan. Nonetheless scaling up the benefit temporarily was a ready response for the Kyrgyz Republic in the face of food price increases in 2008.

Guatemala has implemented a new CCT program (Mi Familia Progresa) since 2008, now covering 900,000 families - enough to cover about a quarter of the population. In addition to the basic classic elements of a $\mathrm{CCT}$, given the high initial malnutrition rates in Guatemala, this program puts extra focus on nutrition, building up community based nutrition services and providing micronutrient supplements. In the context of a crisis response, the program's rural focus implies a gap in urban areas.

Pakistan has implemented a new UCT program (the Benazir Income Support Program) since 2009 The program's initial phase rolled out with beneficiaries selected by Parliamentarians, but as the program expanded it developed a proxy means testing system for new entrants and carried out re-targeted exercises for the initial beneficiaries. As of summer 2011, the transition is nearly complete, with about 1.5 million families eligible. Despite striking progress in scaling up its safety net, Pakistan faces a multitude of shocks, such as floods, which make effective response a particular challenge. 
Bangladesh differs in having its response capacity spread among several programs in operation for at least five years, each progressively targeted but with coverage of less than $10 \%$ of the poorest quintile and concentrated in rural areas. The key programs used to respond to the food crisis are fairly well targeted to the poor. The main program providing coarse rice in rationed quantities in open markets (OMS) is a selftargeted program for the poor as the non-poor have few incentives to stand in long lines for small quantities of inferior quality rice. Moreover, the Vulnerable Group Feeding (VGF) program is targeted at the more geographically food-insecure parts of Bangladesh using a food-vulnerability map developed by WFP. Within these districts, various targeting criteria are used to identify the extreme poor - around $60 \%$ of VGF beneficiaries are from the bottom $40 \%$ of the population. Additionally, the recently established Employment Generation Program has been recently assessed as well targeted and generally effective. It could potentially be used as an additional mechanism of response and its ongoing presence already assists 2 million poor households, 1.5 per cent of total population.

India has many safety net programs, with 3 very large ones highly pertinent to the issue of rising food prices. India's headline program is the Mahatma Gandhi National Rural Employment Guarantee Scheme, which provides up to 100 days of employment for adults in rural households. The scheme is the largest public works program in the world, and one of the very few that operates with a guarantee. Administration is delegated to the states and there is wide variation in the quality and performance of the program across states and districts - excellent in some places, less so in others. India also has a very large system of public ration shops selling staples at subsidized prices to people who hold 'below the poverty line' cards. The PDS is acknowledged to suffer serious issues of governance and diversion of benefits. The 'below the poverty line' card system is also a somewhat problematic version of a unified benefit registry. The Mid-day Meals program provides hot lunches to 120 million school children.

Indonesia has had for several years well designed sector-specific safety nets in health and education, and a community targeted program that grants access to subsidized rice rations (Raskin). The Raskin program has large coverage and somewhat progressive incidence, but assessments over the years have shown that communities often share the rations widely rather than target them narrowly. This not only attenuates the progressiveness of the incidence but lowers the total benefit that can be made to reach the poorest. So far it is the safety net response vehicle in the current increase in food prices. In addition to this program, Indonesia is piloting a CCT transfer scheme (covering 720,000 households in 2009) and has done analytic work on developing a nationwide household targeting system. Indonesia quickly introduced a temporary UCT (BLT) in 2005/6 and 2008/9 to offset the welfare effects of subsidy cuts and fuel price increases. In a short time, the program achieved spectacular coverage rates (19 million households or $30 \%$ of population). Though initial BLT beneficiary lists were compiled hastily, there have been improvements in the methods the government uses to identify potential social safety net recipients. The program is not presently operating but the updated beneficiary list is available.

In Mongolia, there is longer experience with universal programs and more limited experience with narrowly targeted programs. Until 2010, Mongolia operated a universal child allowance costing about 2\% of GDP, the Child Money Program, which covered $90 \%$ of the households in the poorest quintile and gave the country experience with administration of cash benefits. The program was replaced with universal cash transfers from the Human Development Fund (HDF). HDF was created as a result of 2008 electoral campaign promises by both main political parties with a purpose to distribute Mongolia's mineral wealth to the country's every citizen. The HDF universal cash benefit was introduced by the Law on Human Development Fund (2008), which sets out the distribution of the total of MNT 500,000 (about 400 USD $^{6}$ ) to

\footnotetext{
${ }^{6}$ The exchange rate of the Mongolian Tugrik (MNT) to US dollar as of July 18, 2011 was 1,182 MNT/1 US\$.
} 
each citizen, payable in monthly installments (fractions of the above amount) until June 2012. Amounts of monthly cash distributions per citizen were MNT 10,000 in 2010 and have been increased to MNT 21,000 (about \$15) per person in 2011-2012. The allocated budget for the program was MNT 324 billion in 2010 and 702 MNT billion 2011. On the targeted side, to mitigate the effects of the food price increases of 2008, the government introduced, in collaboration with $A D B$, a food stamp program for certain vulnerable groups - the elderly not covered by a pension, disabled and others. It is currently covering about 100,000 households. The Government also has envisioned developing a proxy means test and introducing a poverty-targeted benefit, as reflected in the new Social Welfare Law. However, the Law has been pending approval in Parliament for over a year.

Tajikistan is ranked as a country with a weak base to respond mainly since it currently does not provide targeted support to a large number of the poor, and a large scale response would require fundamental changes to range, size, or targeting of programs and significant building of institutional capacity. Tajikistan's response to the 2008 global food price crisis was constrained by the lack of a poverty-targeted and well-controlled mechanism for channeling assistance to the poor. A study of the Tajikistan Safety Net in 2009 showed that coverage of the poor was low, and found much leakage of payments to the non-poorsocial assistance covered only $20 \%$ of the poorest quintile of households and only $23 \%$ of social assistance payments reached the poorest quintile. Moreover, benefit payments were meager: social assistance amounted to less than $3 \%$ of the per capita monthly consumption of the poorest $20 \%$ of the population, the lowest in Eastern Europe and Central Asia. The Government is now taking steps towards a more credible and effective system of social assistance. Priority areas involve the consolidation of the two existing social assistance programs into a single benefit, targeted to the poorest $20 \%$ of the population (and decoupled from the consumption of electricity and natural gas) and development of a national registry of social assistance clients.

In the least prepared countries - Afghanistan, DRC and Haiti - the existing base of safety nets is characterized by fragmentation, small programs and poor systems development. All are fragile countries with a proliferation of small programs, against a background of fragmented policy. Donor and NGO partners will continue being an essential part of the policy dialogue, given their primary role in protecting the poor and vulnerable in humanitarian need. Since donors - especially World Food Program (WFP) handle many of the functions, the nature of the capacity constraint to scale up is quite different than in government-led systems. In Afghanistan, food aid is the core safety net, delivered via a mix of emergency feeding, school feeding, and food for work. The food for work program puts heavy emphasis on improving the country's damaged infrastructure. WFP has just piloted a voucher program, with plans to reach 30,000 households in a handful of cities in 2011. The Bank is working with government to pilot a UCT with assessment due in summer of 2011 and the possibility of scale-up being financed in a new IDA project. In the DRC a large social fund and a variety of humanitarian efforts have been active, but little in the sense of a solidified safety net. A new pilot CCT and in-kind transfer program are being developed with as yet negligible coverage rates of the poor. In Haiti, while a number of safety nets programs ranging from food for work to cash transfers to school feeding have been developed by Government, donors, and NGOs, funding and coverage are limited and do not cover all the neediest. Administrative capacity is weak and fragmentation is notable. The Ministry with the mandate for safety nets is grossly underfunded ( $1 \%$ of total internal budget) and under-staffed. Rising food prices threaten to unravel some of the progress in building capacity and response in aftermath of January 2010 earthquake, with the potential to cause social unrest. 


\section{Further Considerations and Limitations}

Based on the case studies outlined in Section 4 a number of caveats are worth considering in the interpretation of the assessment framework.

- Concern is broader than the 13 countries identified in Section 3, which reported a quick snap shot of volatility and response capacity based on data estimates from June-December 2010 estimates. The list may change over time - if world prices stay high, or rise higher, additional countries may see pass through to domestic prices, especially if future local harvests are less robust and countries import more from the international market. Indeed, some months on some amendments are warranted. For instance, the emerging drought situation in the Horn of Africa raises concern in Ethiopia, Kenya and Somalia, and possibly in adjacent countries.

- The outlook on food price volatility is dynamic and the data do not provide much in terms of an early warning signal of future risks. Because prices change continuously it is sensible to look beyond the 13 countries assessed in depth. At the time of this analysis, regional assessments by World Bank staff had just been completed, using various criteria relating to share of food (or grain) imported and fiscal position, sometimes in combination with criteria about offsetting commodity prices, initial or forecast poverty rates. With these methods each region identified lists of countries of greatest concern, about half a dozen per region, predominately low income. A recurrent theme in these is that outside ECA and Latin America and Caribbean Region (LCR), good safety net bases for response are relatively uncommon. Regional outlook highlights are summarized in Table 3.

- It should also be noted that countries are exposed to multiple risks, in addition to food price shocks. For example in MENA currently, conflict and political instability present new issues that further threaten the livelihood of the poor in fragile countries in the region (e.g. Yemen). This poses additional challenges to the readiness to respond to food price increases. Similar issues can be identified also in the African context.

- The determination of a country's state of readiness is based on an analysis of available household survey data, program information and guidance from country teams, but inevitably the assignment of a category involves a great deal of judgment. The assessment of administrative capacity is multi-dimensional and somewhat subjective. Moreover, the use of 'progressive targeting' as a criteria to assess whether a countries safety net program is prepared for crisis, is subject to some debate, as outlined earlier. To give the criteria heavy weight would risk equating countries with very little social protection system (e.g. Afghanistan, DRC) with countries like Mongolia that, on one hand have an extensive SP system including a universal transfer program which could be quite effective, albeit expensive to scale up. On the other hand, a country with only universal instruments may have a very hard time delivering enough assistance to those most in need.

- Finally, as identified in Section 3 the selection of vulnerable countries will depend highly on the criteria used which may not be exhaustive. For instance, one short coming of the criteria applied on volatility is that it misses instances where food prices have remained persistently high and where consumers continue to suffer hardship - a factor which most likely explains the absence of any MENA country in the snapshot summary reported. 
Table 3: Summary of World Bank Regional Assessments of Food Price Vulnerability - March 2011

\begin{tabular}{|c|c|c|c|}
\hline Region & Countries of Concern & $\begin{array}{l}\text { Food Price } \\
\text { Volatility } \\
\text { Criteria }\end{array}$ & Preliminary Safety Net Readiness Issues \\
\hline SSA & $\begin{array}{l}\text { First Tier: Ethiopia, Mauritania, } \\
\text { Mozambique and Sudan } \\
\text { Second Tier: Kenya, Cape } \\
\text { Verde, Zimbabwe and Burundi }\end{array}$ & $\begin{array}{l}\text { Wheat } \\
\text { consumption } \\
\text { prices }\end{array}$ & $\begin{array}{l}\text { Countries are heterogeneous in safety net } \\
\text { presence, coverage and administration. Many } \\
\text { have been strongly affected in } 2007 / 08 \text { (e.g. } \\
\text { Ethiopia, Kenya) and have some capacity to } \\
\text { respond. Others are much less prepared e.g. } \\
\text { Burundi, Sudan, Zimbabwe }\end{array}$ \\
\hline MENA & $\begin{array}{l}\text { Jordan, Yemen, Djibouti, } \\
\text { Lebanon, Iraq, and Tunisia }\end{array}$ & $\begin{array}{l}\text { Relative exposure } \\
\text { to food price and } \\
\text { quantity risk as a } \\
\text { function of fiscal } \\
\text { balances and } \\
\text { dependence on } \\
\text { food imports. }\end{array}$ & $\begin{array}{l}\text { In the wake of the new food crisis, there is } \\
\text { evidence that some governments are raising } \\
\text { subsidies, or at least suspending their reform, to } \\
\text { avoid popular discontent. As most of the policy } \\
\text { responses to rising food prices since } 2008 \text { have } \\
\text { overwhelmingly focused on short-term } \\
\text { mitigation measures, these countries face the } \\
\text { new crisis without scalable and effective safety } \\
\text { nets. }\end{array}$ \\
\hline ECA & $\begin{array}{l}\text { Armenia, Tajikistan, Kosovo, } \\
\text { Albania, Moldova, Serbia, } \\
\text { Romania, and the Kyrgyz } \\
\text { Republic. }\end{array}$ & $\begin{array}{l}\text { Countries with } \\
\text { high food budget } \\
\text { shares and high } \\
\text { poverty lines. }\end{array}$ & $\begin{array}{l}\text { Most countries in ECA have at least one targeted } \\
\text { safety net program, and many also have } \\
\text { programs to protect vulnerable groups such as } \\
\text { children and the disabled. }\end{array}$ \\
\hline LCR & $\begin{array}{l}\text { First Tier: Haiti; Grenada and } \\
\text { St. Vincent and the Grenadines, } \\
\text { El Salvador, Jamaica, and } \\
\text { Suriname. } \\
\text { Second Tier: Guyana and } \\
\text { Nicaragua; Dominica and St. } \\
\text { Lucia; Belize, Dominican } \\
\text { Republic, Guatemala, Trinidad } \\
\text { and Tobago; and Venezuela }\end{array}$ & $\begin{array}{l}\text { Countries with } \\
\text { high net food } \\
\text { imports as a } \\
\text { percentage of } \\
\text { GDP, overall } \\
\text { terms of trade } \\
\text { and fiscal space, } \\
\text { presence of safety } \\
\text { nets. }\end{array}$ & $\begin{array}{l}\text { LCR includes a mix of IBRD and IDA countries, } \\
\text { with strong track records and experience in } \\
\text { safety nets. Despite relatively higher capacities, a } \\
\text { challenge for many programs will be to retain } \\
\text { flexibility in scaling down benefits post crisis, } \\
\text { tackling exclusion errors. }\end{array}$ \\
\hline EAP & $\begin{array}{l}\text { Mongolia, Indonesia, Vietnam } \\
\text { and China. Pacific Islands: Fiji, } \\
\text { Samoa, and Kiribati, }\end{array}$ & $\begin{array}{l}\text { Year on year food } \\
\text { price inflation }> \\
10 \%\end{array}$ & $\begin{array}{l}\text { The region is highly diverse with some countries } \\
\text { presenting long established safety net } \\
\text { frameworks and others of a more nascent } \\
\text { variety, requiring strong capacity support. In } \\
\text { most cases safety net systems are either nascent, } \\
\text { or in need of rationalization to be more efficient } \\
\text { or sustainable. }\end{array}$ \\
\hline SAR & $\begin{array}{l}\text { Vulnerable (Short Term): } \\
\text { Afghanistan, Maldives, Nepal } \\
\text { and Pakistan } \\
\text { Vulnerable (Medium Term): } \\
\text { Bangladesh, Bhutan }\end{array}$ & $\begin{array}{l}\text { WFP/Maplecroft } \\
\text { Food Security Risk } \\
\text { Index } 2010\end{array}$ & $\begin{array}{l}\text { High levels of vulnerability and large coverage } \\
\text { requirements across many countries are a major } \\
\text { policy challenge in response. Safety net and } \\
\text { social protection systems in most countries are } \\
\text { nascent, and strong capacity support required. }\end{array}$ \\
\hline
\end{tabular}

Source: internal briefing notes, February, 2011 


\section{Strategic Issues Facing Countries in Mounting Safety Net Responses}

\subsection{Determining the most appropriate response - Lessons from previous crises.}

The quickest, lowest cost and most sufficient safety net response will be to increase the value of a transfer already well targeted and with high coverage of the poor. A number of upper middle income countries, especially in Latin America and Eastern Europe, had such vehicles in place in 2008. For example, Brazil increased the basic benefit of Bolsa Familia in July 2008 by $8 \%$ and the transfer per child by $13 \%$. The program was already targeted to the chronically poor who spent a high share of income on food and thus were most affected. A recent paper shows that the response was particularly beneficial to the urban poor, who did not benefit from increases in income as a consequence of the price increase. While the response was not large enough to fully protect them, it did ameliorate the impact of the price increases (Ferreira, Fruttero, Leite, and Luchetti, forthcoming). Mexico, another example, raised the benefit of Oportunidades in spring 2008, not by the usual adjustment for inflation, but by more since food prices had increased more than general inflation and the goal was to maintain the beneficiaries' ability to purchase their food basket. In Latin America the established programs tend to be CCT, in Eastern Europe they tend to be UCTs. For the purposes of crisis response the conditions are not the important characteristic. The salient thing is that programs already are in place, with a client base who may need extra assistance and that are reached with established channels.

The next best option is to work with transfer programs that are well targeted but with lower coverage. An increase in benefit will help immediately those covered. An increase in coverage may be arranged as well but will take more time and concerted administrative effort along with sometimes minor policy changes. In some cases, the eligibility threshold will need to be raised, in some cases more active outreach will be needed to draw in those already eligible. In Eastern Europe, for example, a number of countries have programs designed as entitlements and were expected to have seen automatic significant increases in coverage in 2008/9 when the crises hit, and yet most did not. In some there were brakes on entry such as requirements to be unemployed for a minimum period, very low eligibility thresholds, subtle barriers in administrative systems or capacities, or clients had little knowledge of the social assistance options and programs had little by way of outreach efforts. In some countries existing programs with limited coverage may be expanded. In 2008/9 for example, El Salvador rolled out its new rural CCT program more quickly than originally programmed, though stopping at the originally planned 100 poorest municipalities. The fact that the program already had a set of procedures and systems in place or under development assisted in the increase in coverage.

In-kind/food distribution will be appropriate where markets are functioning poorly, where foreign assistance is only available in-kind, or where strategic grain reserves need to be rotated. During the 07/08 food crisis, school feeding programs became particularly important in a number of low income countries since they had small but existing programs that could be quickly scaled up e.g. Haiti, Liberia, Senegal and Togo. In such contexts, school feeding provided temporary income support to households, with the link to schooling helping to maintain enrolment. However, targeting errors may be a concern in school feeding programs, since they are usually targeted only geographically and not to the poorest households in participating communities. Thus very large scale programs may include children from less poor families. Or to avoid this, programs are kept small, limited to only very poor areas and thus are unable to cover the poor within less poor areas. Also in the $2007 / 08$ crisis some countries with payments in cash failed to sustain their real value, creating a preference among clients for combination of cash and in-kind food payments not related so much to the inherent pros and cons of food versus cash, but to the 
total value of transfer. Sabastes-Wheeler \& Deveraux (2010) examine this issue in the context of Ethiopia's PSNP program.

It is difficult and time consuming to mount new programs but countries can make progress with determined effort. To run a program reasonably well, a number of tasks must be accomplished and these require administrative capacity. It can take years for a program to reach a mature and really sound level of functioning, even well established flagship programs continue to innovate and improve 10 or more years after initiation. The Philippines was already piloting a CCT program when the food, fuel and finance crises hit in succession in 2008. With this impetus, the government decided to roll out the program much more quickly than initially envisioned. In February 2008 the government launched a CCT pilot with just 6,000 households in 4 municipalities and 2 cities; by end-2009, the program had 700,000 household beneficiaries nationwide; scaling up to 1 million by end-2010 and an estimated 2.3 million (out of 4.2-4.3 million poor families) by the end of 2011. This is a huge accomplishment, with the speed of roll out challenging the ability to develop sound technical systems, and yet it illustrates the usual time frame for even determined efforts to get to scale.

Where administrative frameworks are lacking, countries often resort to across the board market and trade interventions, which are typically regressive in their impact. In the 2007/08 food crisis, many countries did not have the administrative frameworks in place to be able to implement safety-net measures at short notice. They therefore made blanket market and trade interventions that proved sometimes ineffective or costly, or both. A poll of World Bank country economists in the second quarter of 2008 shows that the most common short-run responses to household food insecurity have been acrossthe-board actions that affect prices rather than more targeted safety nets. A similar survey of IMF country desk officers shows that 33 countries had reduced taxes on fuel and 29 countries had increased subsidies by 2008. Such measures, when they delivered some relief did so irrespective of need. This re-emphasized the importance of contingency planning to better equip countries to be able to deliver targeted assistance where it is most needed (See Box 1 for the Middle East experience with food subsidies).

Nutrition programs should be considered as part of the likely policy response, especially but not only where malnutrition rates were high before food price increases. Growth monitoring can detect where children are falling into trouble, nutrition education can help households make the most of scarce resources, and micro-nutrient interventions gain importance as dietary diversity declines. If food is distributed in kind as part of safety net programs, it is desirable that it be fortified. More generally micronutrient delivery systems are needed in parallel with transfer programs. For example, in confronting the price increases in 2008, the Kyrgyz Republic and Tajikistan developed programs to provide micro-nutrients to pregnant and lactating women and children. ${ }^{7}$

Unfortunately the existence of technically sound program options does not always prevent less sound policy choices. Despite the well-established, well-evaluated poverty targeted CCT programs in Jamaica and Mexico, the countries' first round of policy responses in 2007/8 did not rely principally on them, but instead on price subsidies. Only as a second round of policy action was the change made in both countries to replace the price response with increases in coverage and benefits of the CCT programs. In Georgia in

\footnotetext{
${ }^{7}$ Under GFRP responses, the Kyrgyz Republic provided nutritional supplements and education to 143,000 pregnant and lactating women and 500,000 children under 5; with Tajikistan providing Vitamin A supplements and nutrition education for 200,000 women nationwide, iron and folic acid supplements for women in two oblasts, food packages for undernourished women receiving prenatal care, delivery or vaccination in primary health care centers in poorest areas.
} 
March 2011, despite the existence of its well-targeted social assistance program, the country has chosen a one-off flat and universal cash payment.

\section{Box 4: Food Subsidies in the Middle East as Response to Rising Food Prices in 2007/2008}

The poor in the Middle East were disproportionately exposed to the fallout of the previous food crisis (2007/2008). Where data exist, they show increasing poverty and social tensions because:

- Countries in the region rely on imports to a greater extent than many other countries to meet their food needs, with as much as $50 \%$ of consumed food imported;

- Food staples (prices of which were rising the fastest) occupy a large share of poor households' consumption, making them vulnerable to price shocks;

- Countries in the region had, even before the crisis, relatively high malnutrition rates for their level of income, making any further deterioration socially painful.

- The lack of adequate well targeted safety nets left policy makers without a proper instrument to help the poor to withstand increased prices, instead they relied on general subsidies which are only partly effective to protect the consumption of the poor.

- The reliance on food (and fuel) subsidies put the governments at significant fiscal risk as well. The food subsidy bill in Morocco, Tunisia, and Egypt grew by 0.5-1.5 percent of GDP between 2005 and 2008.

\subsection{Even when there is a strong base for response, there are limitations to achieving full coverage of all those most affected by increased food prices.}

Some programs will have exclusion errors caused by explicit design features. Several programs that might anchor a country's response (e.g. Guatemala's Mi Familia Progresa and Bangladesh's Vulnerable Group Feeding and 100 Days Employment) focus on rural areas where chronic poverty is traditionally more widespread and deeper than in urban areas. In the face of rising prices, however, the urban poor are also affected, and have much less ability to cover part of food consumption out of own production. Similarly, CCT programs that are the backbone of social assistance in a growing number of countries, especially in Latin America, are usually designed for families with children from birth to school age. Households without school age children go uncovered or covered by other programs that are not principally poverty targeted (e.g. social pensions, or disability assistance, etc) ${ }^{8}$. And some CCT programs work only in locations deemed supply ready", excluding thereby some areas, which are often poor and/or remote.

Overcoming such exclusions suggests the use of complementary programs where possible. Mexico has used its less conditional Programa Alimentaria in areas too remote or with too few services for Oportunidades co-responsibilities to work effectively. Bangladesh has opened its open market sales program - a self-targeted program to buy small amounts of rice at subsidized prices. Another option is to make structural changes to existing programs, but these need to be considered carefully as there is the potential that they would not be helpful to the programs longer run goals.

All programs suffer imperfections in coverage - errors of exclusion are a painful fact of life in social protection. Programs that minimize transactions costs and stigma, and that have good outreach will have lesser problems of exclusion, but there is some irreducible minimum in even the best of programs. Any

\footnotetext{
${ }^{8}$ The programs in Brazil, Ecuador, Jamaica and Mexico are exceptions; they cover poor families irrespective of the presence or absence of children, but provide lower benefits to them.
} 
attempt prompted by rising food prices to lower such under-coverage is useful not only to the new urgency but to program's long run goals as well.

Many programs have relatively static targeting systems. Many programs around the world, especially in Latin America but including a number of those in the 13 countries looked at in detail in this paper, use proxy means tests as their targeting system. In these, the eligibility threshold is not a simple estimate of purchasing power and so is not straightforward to adjust to keep a steady value in the face of food price volatility. Moreover, a number of countries do not allow households to register year long as they are formed or feel hardship; in these countries registration is confined to defined periods and/or the number of recipients is capped to fit a certain budget envelope. These factors do limit response, though because the bigger hardship from the rise in food prices comes not from people thrown newly into poverty, but rather from exacerbated poverty of the already poor, the limitation is not so bad in the face of rising food prices as it has been in a loss of sudden loss of employment or income that characterized the financial crisis.

\subsection{There are strategic questions to face about how to increase benefits or coverage and how to scale down again.}

In increasing benefits or coverage in the face of food price increases, it is important to consider from the outset whether they should be scaled down if/when food prices drop. Sometimes the answer is no - a country may be prompted by the increased food prices crisis to take a policy action to improve the benefit levels or coverage of their safety net. But some countries with good coverage and reasonable generosity may wish to ensure any increased benefits are of a temporary nature and can be scaled down. Some examples from responses to the 2008 price increases show some of the options and tradeoffs.

- Temporary increase in benefit: In the Kyrgyz Republic, the flat rate benefit for those in the Unified Monthly Benefit program was topped up by about $30 \%$ for a few months.

- Indexation: The benefits of Brazil Bolsa Familia's were not indexed and since the beginning of the program in 2003 they had been adjusted only once (July 2007). Hence the real value of the benefits was eroding even before the food price spike. Rising food prices helped trigger an increase that boosted the real value of the transfer. This left no need for a scale down later. Indeed, since food prices rose more than $\mathrm{CPI}$, it did not fully compensate poor households whose budgets are highly skewed towards expenditure on food.

- One-off benefit: In Chile, the government granted two one -off payments to the currently registered beneficiaries of several of its core social protection programs, which altogether had a high coverage of the poorest $40 \%$ of the population.

- Change in benefit structure: In Mexico, the benefits of Oportunidades are indexed, but a decision was taken in spring 2008 to increase them by more than the $\mathrm{CPI}$, by enough to allow households to purchase the food basket they could before food price rises. The benefit was structured as a separate benefit, in the panoply of different Oportunidades benefits (named Vivir Mejor). It has, however, remained in the benefit structure rather than being removed or eroded away.

\section{The World Bank is Moderately Ready to Help Countries Respond}

The Bank has active engagement on safety net issues in the 13 countries on the watch list and extensive engagement in 10. In several cases - Azerbaijan, Afghanistan, Bangladesh, Guatemala, Georgia, Haiti, Indonesia, the Kyrgyz Republic, Mongolia, and Pakistan, the engagement of the country and the World Bank is extensive. The engagement has been active for several years, involves not just diagnostic issues but 
implementation issues, and/or involves both analytic and advisory services and lending supervision or preparation, and is sometimes focused on more than one program. In other cases - the DRC, India, Tajikistan, the engagement with the Bank on safety net issues is much newer or more limited. These incipient dialogues have been assisted by the Central Contingency Fund in Indonesia ${ }^{9}$, and the Rapid Social Response (RSR) Multi-Donor Trust Fund in Tajikistan and the DRC. Haiti has received support through all three of the trust funds - Global Food Price Crisis Response (GFRP), RSR and Japanese Social Development Fund (JSDF).

Factors hindering safety net response in poor countries in $\mathbf{2 0 0 8}$ (to the triple wave of food, fuel and finance crises) included both financing and the lack of scalable safety net programs. The Bank and other donors tried to address these with various instruments. It is instructive to consider how what was done places us today, especially since price volatility may affect additional countries where starting capacities are significantly less than the subset currently reviewed.

The experience in the past crises was that the GFRP and IDA Fast Track gave tools to the Bank to move money with expedited procedures and IDA lending for safety nets did increase, albeit not as early as expected and with the inherent constraints of overall IDA allocations. IDA's lending volume under the Safety Nets Theme code (54) doubled from \$735 million in FY05-07 to \$1,418 million in FY08-10. This lending has been spread thinly across 35 IDA countries during FY08-10. IDA lending for crisis response has typically been devoted to countries with pre-existing Bank engagement and established programs. The lending has been boosted by the opening of an IDA Crisis Response Window in 2008, which provided \$144 million financing for 15 projects in 13 countries $^{10}$.

Trust fund financing was mobilized via GFRP, RSR and JSDF and they have provided $\$ 207.82$ million for 67 safety net projects in $\mathbf{4 2}$ countries, including 22 in the Africa region. A striking feature of response is the sheer volume of activities generated. Another is that it includes 19 countries without any previous lending for or analytical activities about safety nets ${ }^{11}$. Response options included a mix of emergency projects focused on direct and indirect transfers, nutrition as well as capacity building (see Annex 3). Efforts have particularly focused on fragile contexts, where one might expect a disproportionate impact of crisis e.g. Sierra Leone, Liberia, Haiti, Togo, Papua New Guinea, and Nepal.

While the small size of these trust funds has been insufficient to provide protection of all those at risk, they have provided short term emergency support to smooth consumption amongst some of the vulnerable groups. In Liberia, a cash-for-work program initiated under GFRP benefitted 17,000 beneficiaries. In the Kyrgyz Republic, distribution of Vitamin A took place to 154,000 pregnant women and 550,000 children under age five in June 2009. Additionally, the average Unified Monthly Benefit (UMB) of around $\$ 3.5$ per month has been topped-up by KGS 35 (less than \$1). In Haiti, school feeding was provided to 135,000 children.

Building on the GFRP, the RSR and JSDF have focused on building capacity across a series of low income countries, thereby moving the Banks support towards a medium term framework and beyond emergency programming. All combined the RSR and JSDF trust funds are supporting 29 countries through 45 technical

\footnotetext{
${ }^{9}$ The central contingency fund provided a three year boost to the World Bank's internal operational budget for safety nets and nutrition work for FY09-11 in order to help clients develop such responses to the food, fuel, and finance crises.

${ }^{10}$ Crisis Window recipient countries include Benin, Comoros, Ghana, Honduras Kenya, Kosovo, Liberia, Malawi, Mongolia, Nepal, Sierra Leone, Tanzania.

${ }^{11}$ Cameroun, Central African Republic, Comoros, Djibouti, Gambia, Ghana, Guinea-Bissau, Haiti, Kenya, Laos, Lesotho, Liberia, Maldives, Mongolia, Papua New Guinea, Sierra Leone, Sudan, Togo, West Bank \& Gaza.
} 
assistance projects to initiate policy dialogue and capacity building in support of safety net strengthening. Seed financing to support capacity development is small - under \$1 million in 19 of the client countries. These responses have in some cases opened the door to substantive dialogue or started to build capacity for program administration. In Nepal, for example, the Government is being supported to improve the delivery of cash-based social safety nets, through technical assistance and capacity building to the Ministry of Local Development and piloting a CCT program. In Papua New Guinea, support is being provided for capacity-building and oversight to ensure that the training and public works are targeted to poor applicants and monitored and evaluated rigorously, and that social accountability mechanisms perform effectively. The grant leverages the IDA project approved in January 2011.

It should be noted that the financing is of a limited time period at present and many country projects will soon reach their conclusion. Average project life span by design is approximately 15 months. By end of 2011, over half of the technical assistance projects currently supported by RSR and JSDF will have concluded, thereby fully phasing out current technical assistance support in 10 countries, and reducing it in another 6 . The majority of other technical assistance projects will conclude by 2012.

Some of the extraordinary resources brought to bear to assist in 2008-10 are ending. The primary responsibility for safety net projects passed from the GFRP to the RSR trust funds once they came on line. For the RSR, the latest call for proposals was issued in March 2011 and the final round is scheduled for September 2011. The JSDF Emergency Window opened in 2010, to run for approximately three years. The phasing down of technical support during a resurgent crisis raises some concerns, suggesting that continued investment and dialogue would be needed to sustain such efforts.

\section{Conclusions}

The review has provided a thumbnail sketch of the readiness of safety nets in $\mathbf{1 3}$ countries to respond to rising food prices. The assessment uses simple, qualitative criteria: the presence of safety net programs, program coverage, targeting effectiveness and administrative capacity.

The review highlights strong variations in safety net preparedness across the 13 countries included in the assessment. Just 1 country is considered to have a strong basis for response. 8 countries are classified a moderate base for response and 4 countries are either weakly prepared or not prepared at all. Yet even in countries classified with a moderate or strong basis for response a number of strategic decisions challenge effective implementation e.g. how to scale down benefits post crisis, how to increase coverage using programs that target specific categories or geographical areas.

The findings suggest that despite a relatively stronger level of preparedness across many countries, a medium term agenda remains - especially since concern extends beyond the narrow range of countries currently presented. Priority areas of action may include the development of at least one sound poverty targeted program in countries without such; developing agile targeting systems, especially allowing ondemand application; and ensuring that the mix of programs and instruments are suitable for crisis response as well as for combating chronic poverty and inequality.

The findings presented have global implications beyond the sub-set of countries assessed. Regional data presented confirms an uncertain outlook on food prices across a much broader set of countries, compounded further by slow recovery from the $2007 / 08$ price shocks and escalating fuel prices. There is a strong rationale therefore for the continued investment and scale up of safety nets in order to mitigate poverty impacts and help prevent future losses. 
From the perspective of the World Bank, this also has implications in terms of sustaining support for safety net preparedness both in good times and bad through mechanisms such as the Rapid Social Response Program (RSR). Trust fund financing through GFRP, RSR and JSDF has provided \$ 199.5 million for 66 safety net projects in 41 countries, including 21 in the Africa region. However, financing is of a limited time period and many country projects will soon reach their conclusion. The phasing down of technical support during a resurgent crisis raises some concerns, suggesting that continued investment and dialogue would be needed to sustain such efforts.

The current assessment, combined with lessons from recent crises, bring to light a number of priorities to guide safety net crisis preparedness going forward. Priority areas include:

- Developing real time monitoring instruments to understand the level of risk and response readiness of client countries. In this context, better use of early warning information should be prioritized to best understand the unfolding level of risk in different contexts.

- Putting in place the basic administrative structures of needs-based safety nets.

- Promoting an integrated response of actions, combining diverse safety net instruments, along with other sectoral interventions in nutrition and agricultural investment.

- Making financing and technical expertise available in a timely manner, yet focused beyond the short term

- Working to enhancing the evidence base of how impacts are manifest and what works in times of crisis. 


\section{References}

Araujo, M. Caridad. 2006. "Mongolia Assessment of the Child Money Program and Properties of its Targeting Methodology." Paper No. 2006-1, World Bank. Washington, DC.

Asian Development Bank. 2006. "Indonesia: Social Protection Sector Development Program." Performance Evaluation Report. Washington, DC.

Barrientos, Armando, Miguel Niño-Zarazúa and Mathilde Maitrot. 2010. "Social Assistance in Developing Countries Database." Brooks World Poverty Institute, the University of Manchester. Manchester, United Kingdom.

Brinkman, H., de Pee, S., Sanogo, I., Subran, L. and M. Bloem. 2010. "High Food Prices and the Global Financial Crisis Have Reduced Access to Nutritious Food and Worsened Nutritional Status and Health." Journal of Nutrition. Supplement: The Impact of Climate Change, the Economic Crisis, and the Increase in Food Prices on Malnutrition. January 2010, 140: 153S-161S.

Comola M. \& L. de Mello. 2010. "Enhancing the Effectiveness of Social Policies in Indonesia." OECD Economics Working Paper No. 810. Paris.

Compton, J., S. Wiggins and S Keats. 2010. "Impact of the Global Food Crisis on the Poor: What is the Evidence?" London: Overseas Development Institute. Available at: www.odi.org.uk/resources/download/5187.pdf.

De Hoyos R., R. Lessem. 2008. "Food Shares in Consumption: New Evidence Using Engel Curves for the Developing World." World Bank. Washington, DC.

D'Souza A. \& D. Joliffe. 2011. "Rising Food Prices and Coping Strategies Household-level Evidence from Afghanistan". Policy Research Working Paper 5466. World Bank. Washington DC.

Farid, Naser. 2003. "Social Protection in Bangladesh: Food Assisted Safety Nets Programs." Power Point Presentation. Government of Bangladesh. Dhaka, Bangladesh.

Ferreira, Fruttero, Leite, and Luchetti. Forthcoming. "The Distributional Consequences of a Food Price Shock in a Large Food-Producing Country: Evidence from Brazil in 2008". World Bank. Washington, DC.

Food and Agricultural Organization. 2011. Global Food Price Monitor. Rome, Italy.

G20 Interagency Paper. 2011. "Price Volatility in Food and Agricultural Markets: Policy Responses". Policy Report including contributions by FAO, IFAD, IMF,OECD, UNCTAD, WFP, the World Bank, the WTO, IFPRI and the UN HLTF

Government of Pakistan. 2010. "Benazir Income Support Programme (BISP)". Power Point Presentation. Islamabad, Pakistan.

Grosh, Margaret , Carlo del Ninno, Emil Tesliuc, and Azedine Ouerghi. 2008. For Protection and Promotion: The Design and Implementation of Effective Safety Nets. World Bank. Washington, DC. 
Hodges, Anthony, Khurelmaa Dashdorj, Kang Yun Jong, Anneclaire Dufay, Uranchimeg Budragchaa, and Tuya Mungun. 2007. "Child Benefits and Poverty Reduction: Evidence from Mongolia's Child Money Programme." Working Paper, UNICEF. New York, New York.

Skoufias E., S. Tiwari, \& H. Zaman. 2011. "Can we rely on cash transfers to protect dietary diversity during food crises? Estimates from Indonesia". Policy Research Working Paper 5548, World Bank. Washington, DC.

International Monetary Fund. 2008. Country Report No.08/76. Islamic Republic of Afghanistan: 2007 Article IV Consultation. Washington, DC.

2011a. Country Report No. 11/31. Georgia: Sixth Review Under the Stand-By Arrangement and Requests for Modification of Performance Criteria, Waiver of Nonobservance of Performance Criterion, Waiver of Applicability of Performance Criterion, and Rephasing of Purchase - Staff Report. Washington, DC.

. 2011b. IMF Country Report No. 11/50 India: 2010 Article IV Consultation-Staff Report. Washington, DC.

. 2010a. Country Report No. 10/113 Republic of Azerbaijan: 2010 Article IV Consultation. Washington, DC.

. 2010b. Public Information Notice (PIN) No. 10/28 2009 Article IV Consultation with Bangladesh. Washington, DC.

. 2010c. Country Report No. 10/88 Democratic Republic of the Congo: 2009 Article IV Consultation. Washington, DC.

. 2010d. Country Report No. 10/36 Guatemala: 2009 Article IV Consultation. Washington, DC.

. 2010e. Country Report No. 10/263 Haiti: 2010 Article IV Consultation and Request for a Three-

Year Arrangement Under the Extended Credit Facility - Staff Report. Washington, DC.

. 2010f. Country Report No. 10/284 Indonesia: 2010 Article IV Consultation. Washington, DC.

. 2010g. Country Report No. 09/209 Kyrgyz Republic: 2009 Article IV Consultation. Washington,

DC.

2010h. Country Report No. 10/294 Mongolia: Fifth and Sixth Reviews under the Stand-By Arrangement and Rephrasing of Purchases. Washington, DC.

2010i. Country Report No. 10/374 Republic of Tajikistan: Third Review Under the Three-Year Arrangement Under the Extended Credit Facility, Request for Waiver of Nonobservance of a Performance Criterion and Request for Modification of a Performance Criterion-Staff Report. Washington, DC. 
2009. Country Report No. 09/265 Pakistan: Second Review and Request for the Augmentation of Access Under the Stand-By Arrangement-Staff Report. Washington, DC.

Lepeshko, Nadezhda . 2011. "Global Food Price Crisis and Safety Nets Response: Experience of IDA Countries in ECA." World Bank. Washington, DC.

Sabates-Wheeler and Stephen Devereux. 2010. "Cash Transfers and High Food Prices: Explaining Outcomes on Ethiopia's Productive Safety Net Programme." Future Agricultures Working Paper. London.

Royat, Sujana. 2009. "The PNPM Generasi: Conditional Cash Transfer for Poor People Driven by Community for Better Health and Education." Government of Indonesia. Jakarta, Indonesia.

Social Protection in Asia. 2009. "Problems and Challenges for the Indonesian Conditional-Cash Transfer Programme -Program Keluarga Harapan (PKH)." Working Paper Issue 04. New Delhi, India.

The National Food Policy Capacity Strengthening Programme (NFPCSP), BRAC Research and Evaluation Division (RED) and BRAC Development Institute (BDI) of BRAC. 2009. "Study on the First Phase of the 100-Day Employment Generation Programme." Dhaka, Bangladesh.

National Statistic Office for Georgia. 2011. Inflation Rate in Georgia, February 2011: Press Release. Georgia.

Ortiz, Isabel, M. Cummins. J. Chai. 2011 "Escaling Food Prices. The threat to poor households and policies to safeguard a Recovery for All". UNICEF. New York.

Wodon, Quentin and Hassan Zaman. 2010. "Higher Food Prices in Africa and Policy Response", The World Bank Research Observer. 25(1):157-176. Washington, DC.

World Bank. 2011a. World Food Price Watch. December 2010. Washington, DC.

. 2011b. "Responding to Global Food Price Volatility and Its Impact on Food Security". Development Committee. Washington, DC.

.2011c. Social Protection Atlas. Washington, DC.

. 2011d. Concept Review and Approval Document. Kyrgyz Republic: Additional Financing to scale-up the Health and Social Protection Project. Washington, DC.

. 2011d. World Food Price Watch. December 2010. Washington, DC.

. 2010a. Press Release "World Bank Provides Additional Support to Afghanistan's National Rural Access Program." Washington, DC.

. 2010b. Project Information Document (PID) Afghanistan Pension Administration and Safety Net Project. Report No.: AB4981. Washington, DC. 
2010c. Project Paper on the National Emergency Rural Access Project (NERAP). Report No: 57776-AF. Washington, DC.

. 2010d. "Tajikistan: Targeting Social Assistance to the Poorest Households." Washington, DC. .2010e. Mongolia Social Protection Brief. Washington, DC.

. 2010f. SP Overview Pakistan Safety Net Report, Chapter 2. Washington, DC.

2010g. Policy Note Vietnam "Strengthening the social safety net to address new poverty and vulnerability challenges." East Asia and Pacific Region. Washington, DC.

2010h. "Social Protection in East Asia and the Pacific." Power Point Presentation. Washington, DC.

2008. "Guidance for Responses from the Human Development Sector to Rising Food and Fuel Prices." Washington, DC

. 2006. "Making the New Indonesia Work for the Poor". Jakarta, Indonesia. 


\section{Annexes}

\section{Global Food Price Increases and Safety Net Readiness}




\section{Annex 1: Recommendations for Safety Net Policy Response}

Policy responses must be chosen based on country context, but there is a loose ranking of programs for the short-run response.

\section{Direct Transfers}

- Targeted cash transfers of adequate coverage, generosity, and quality are the best option.

- The second best option is increasing the benefits across a large spectrum of social transfers, such as social pensions, survivorship pensions, disability pensions, unemployment benefits (where they cover the poor). Food stamps or vouchers have slightly higher administrative costs than cash, but can be politically popular.

- Food distribution in-kind is appropriate where markets are functioning poorly, where foreign assistance is only available in-kind, or where strategic grain reserves need to be rotated. Elsewhere in-kind programs will have higher than necessary administrative costs per unit of value transferred. They also have a limit on how much support can be transferred by beneficiary. Different types of food distribution includes take home rations, school feeding programs, distribution of fortified foods, onsite feeding through health centers; ready to use therapeutic foods in the home.

- Public works programs rarely achieve coverage sufficient to be the whole response to rising food prices, however, where public works programs exist, increasing their benefit or coverage may help. This may often be coupled with the introduction of lighter work-fare, which is easier to organize, involves less supervision e.g. road cleaning, grass cutting etc.

- Where Conditional Cash Transfer (CCT) programs already exist, increasing their benefit or coverage may be a key part of the response. However, establishing new CCTs may take too long and exclude the neediest or those suffering from acute but transitory income shocks.

- Immediate across-the-board wage increases via public sector and minimum wages are not desirable. Both instruments represent a permanent increase in wages in response to a shock that may be temporary, thereby fueling inflation and fiscal expenditures over the long run. They fail to increase wages among the poor, who are concentrated in the private, informal sectors.

\section{Indirect transfers}

- Fee waivers or vouchers for health and scholarships for education help households maintain access to services even if households become poorer.

- Lifeline pricing for networked utilities can be appropriate where the poor are connected to the network, have individual meters, volume differentiated tariffs are used, and the subsidized block of service is consonant with use by low-income households.

- General food price subsidies are distortive, costly, and hard to eliminate, although sometimes adroit choice of commodities can result in transfers that are nearly neutral in incidence and inclusive of the poor. They also have physical limitations (quantities of specific food items consumed) on how much income can be transferred in this way. General fuel subsidies tend to be very regressive, especially those on gasoline. Transport subsidies are more complex, and often not well targeted.

\section{Further considerations:}

- In some, but not all, cases it will be appropriate to scale social protection interventions back down as food prices find their new long term level and households and wages adjust to it, however where safety nets were grossly inadequate it may be desirable to keep them at scale.

- Specific nutrition and health interventions are often needed to complement social protection programs

- The education goals of keeping children in school and learning can be assisted in the face of growing poverty through income transfers and demand-side education interventions. 
Annex 2

Country Profiles 


\section{Main safety net interventions}

- Cash transfer program for families of martyrs and war-related disabled: Paying 220,000 survivors of the recent conflicts and 90,000 disabled beneficiaries. Policy and operational context of this program remains weak. Program consumes less than $0.5 \%$ of GDP.

- National Emergency Employment Program for Rural Access (NRAP): Provides year-round employment and access to basic services through the construction of roads in rural areas, providing 700,000 temporary jobs over a month-length period.

- In kind (food aid) programs: Provide support too poor households through public works programs often in the form of food for work. These programs are operated by both Government of Afghanistan (GOA) and donors and have strong elements of self-selection, as well as direct encouragement to members of the poorest households to participate.

- Program to Support Poor Families in Afghanistan - Unconditional Cash Transfer (UCT): In response to the 2008 food price crisis, the GOA has been developing a well-targeted Social Protection (SP) strategy, including coherent institutional framework and effective delivery mechanisms, through a pilot supported by the IDA-funded Pension Administration and Safety Net Project. The program seeks to establish the institutional groundwork and operational platform for a sustainable national SP system. It will operate with community based targeting (CBT) focused primarily on the rural population.

\section{Key Issues for Food Crisis Preparedness}

- Existing interventions remain small in terms of coverage and funding. The majority of the poor and vulnerable are not assisted directly through government-sponsored programs.

- There are humanitarian programs directly supported by United Nations (UN), bilateral agencies and international NonGovernmental Organizations (NGOs). However, coordination across programs is weak and the line Ministry for SP does not have a thorough understanding of SP programs operated by other ministries, donors or NGOs.

- Over the course of year 2010, the line ministry of SP has been intensively working on preparations for the IDA-funded UCT pilot, including establishing close working relationships and coordination mechanisms with other Ministries and non-government bodies. It is anticipated that by early summer 2011, evaluation of the SSN pilot would be completed and the scale up activities would be considered (a new IDA project in the pipeline). The new program, if evaluated as a success, could become an intervention to respond to various shocks including increased food crisis.

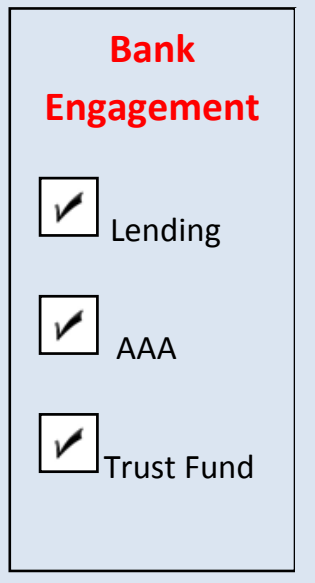

Background Statistics

- GDP per capita US\$ 405 (2008)

- Population 29.8 million inhabitants (2009)

- Poverty rate $42 \%$ (2007)

- Malnutrition height for age $59.3 \%$ and weight for age $32.9 \%$ of children under 5 (2004)

- Fiscal balance \%GDP $-2.6 \%$ (2008); -2.5\% (2010 projection)

Source: WDI and IMF Article IV Consultations

Share of the Poorest Quintile Covered by SSN Programs, Afghanistan 2007
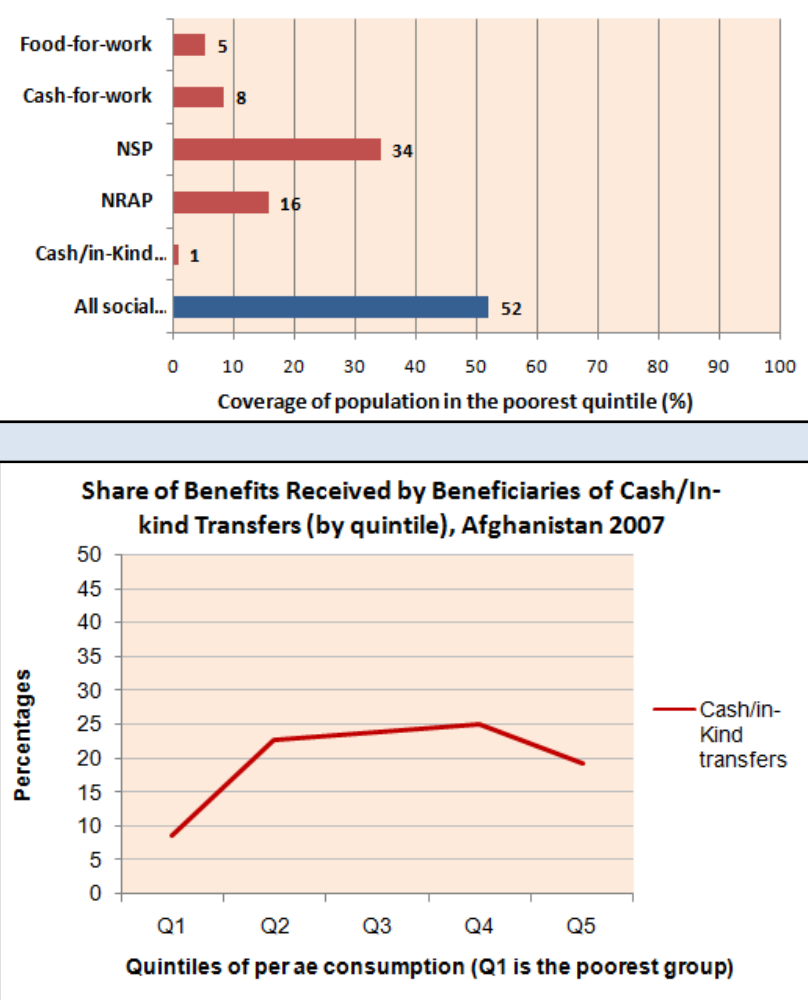

Benefits of the Cash/in-Kind transfers as a Share of Household's base Consumption, Afghanistan 2007

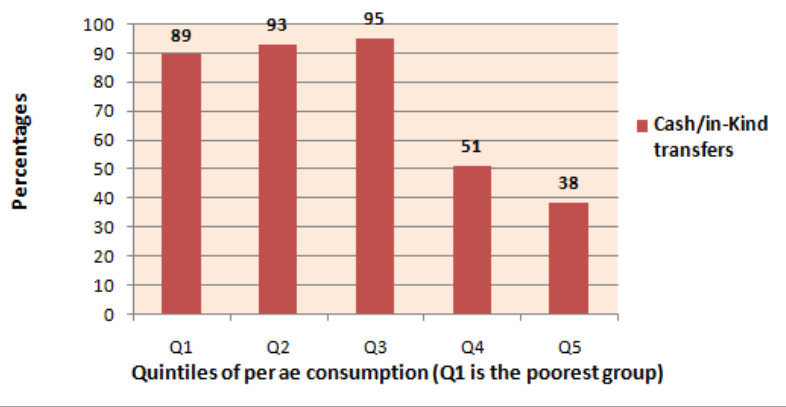

Source: World Bank Social Protection Atlas (Based on Country Household Surveys) 


\section{Main safety net interventions}

\section{Targeted Social Assistance (TSA) Program:}

- Consists of several smaller cash social assistance program consolidated into a regular monthly cash transfer targeted at the poorest population.

- Improvement introduced to the TSA program design and administration led to an expanded coverage. The TSA program now covers close to $10 \%$ of the population, compared to only $4 \%$ at its inception.

- Improved administrative regulations have helped reduce transaction (application) costs for beneficiaries, who now need to produce half as many documents to enroll as previously.

- There is a pilot program to link other beneficiaries with activation programs Social Protection Development Project (Bank-funded): Reform assistance of people with special needs and disabilities. The entire certification system, the network of social and employment assistance services and benefits will be reformed.

\section{Key Issues for Food Crisis Preparedness}

- The Government continues strengthening the SP system by enhancing targeting performance and impact of TSA. 92\% of its beneficiaries received their benefits though ATM cards, which also improved their access to and familiarity with other financial services.

- Business processes are automated in real time connection using centralized Management Information System (MIS) that covers the entire country.

- Administrative system is flexible and there is still room to increase coverage and consolidate social protection programs into one TSA system.

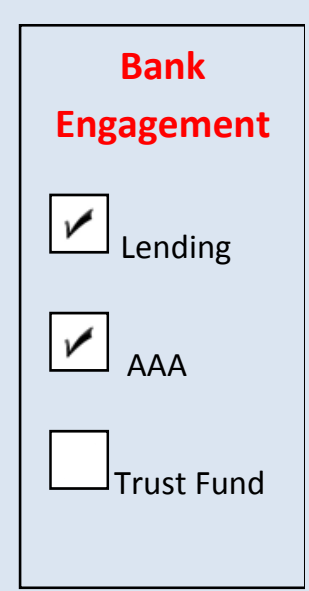

Background Statistics

- GDP per capita US\$ 4,899 (2009)

- Population 8.781 million inhabitants (2009)

- Poverty rate $10.9 \%$ (2009)

- Malnutrition height for age $26.8 \%$ and weight for age $8.4 \%$ of children under 5 (2006)

- Fiscal balance \%GDP $6.8 \%$ (2009); $18.2 \%$ (2010 projection)

Source: WDI and IMF Article IV Consultations, http://www.azstat.org/indexen.php
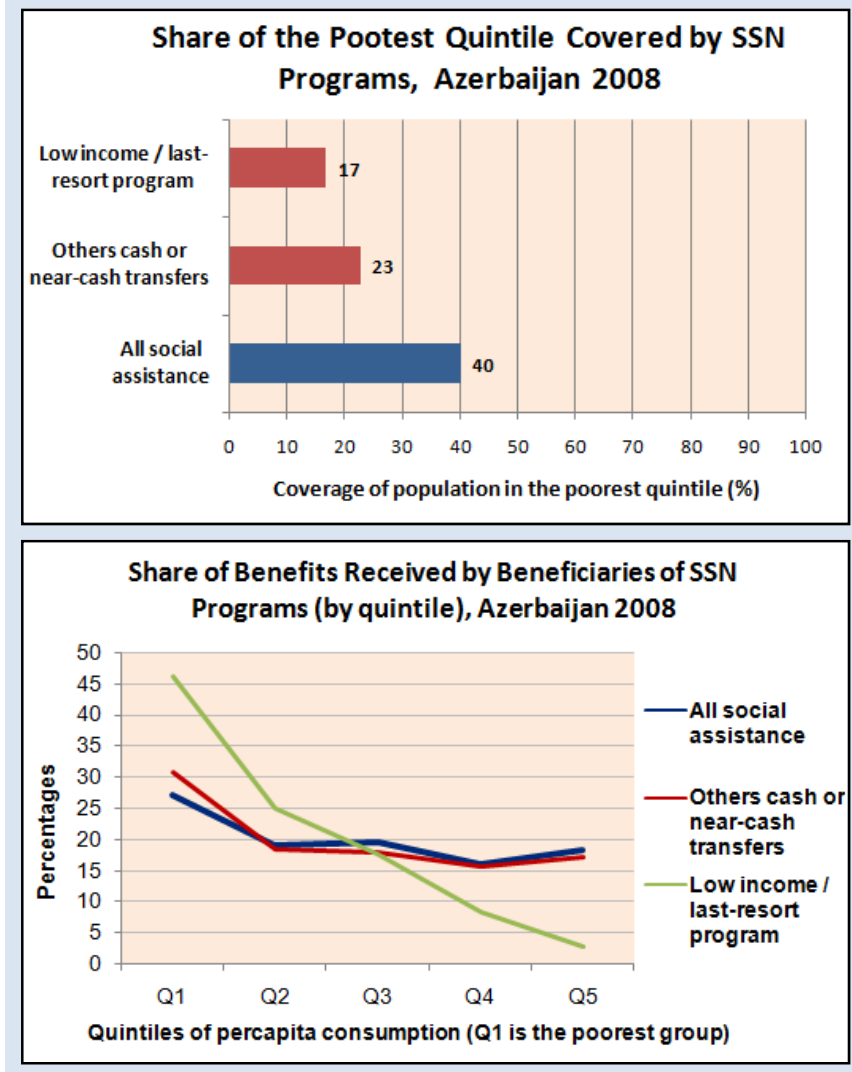

Benefits as Share of Household's Base Consumption in the Poorest Quintile, Azerbaijan 2008

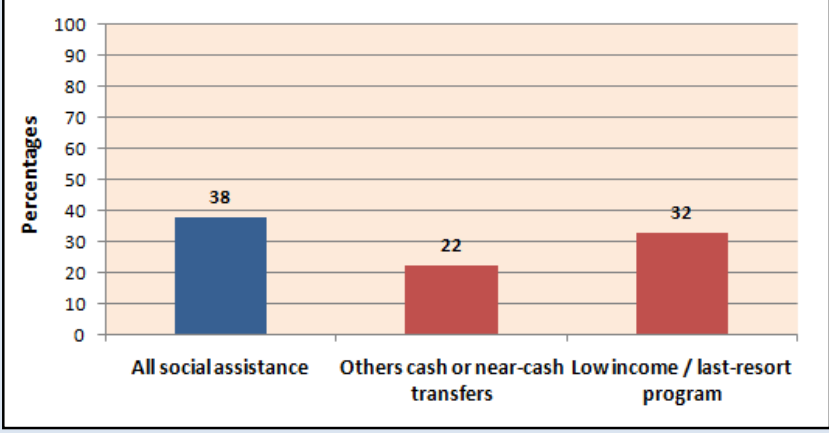

Source: World Bank Social Protection Atlas (Based on Country Household Surveys) 


\section{Main safety net interventions ${ }^{1}$}

- Vulnerable Group Development (VGD): Provides $30 \mathrm{~kg}$ of rice for a period of 24 months to poor women.

- Vulnerable Group Feeding (VGF): Provides monthly food rations to HH affected by disasters and lacking agricultural land and productive assets.

- Employment Generation Program for the Poorest (EGPP): Provide short-term employment on community sub-projects to enable $\mathrm{HH}$ better cope with vulnerability. It currently covers approximately over half a million workers per year (partially funded by Bank).

- Female Secondary School Stipend Program: Monthly Cash Transfer (CTT) conditioned on school attendance, academic performance and girls remaining unmarried.

- An RSR-funded conditional cash transfer pilot aimed at promoting education and nutrition of children from extreme poor families in both rural and urban areas.

- Old Age Allowance: Social pension using community based targeting to select individuals based on eligibility criteria for low monthly cash benefits. Largest cash transfer program in terms of beneficiaries (2.5 M).

- Various other programs: These include Rural Employment and Road Maintenance Program (RERMP), Food for Work (FFW), Test Relief (TR), Hill Tract Area Development (CHT), and Food for Education and Gratuitous Relief (GR).

- GFRP IDA 2008: Fiscal budget support to absorb the pressure from the budget due to the expansion of food-based Social Safety Net (SSN). It helped fully mitigate the impact of food price increases, and disbursed $\$ 82.7 \mathrm{M}$ contributing to maintaining core service delivery to vulnerable groups.

\section{Programs Activated in Direct Response to Food Price Crises 2011}

- Fair Price Ration Card: 2 million cards distributed to poor households allowing purchase of $20 \mathrm{~kg}$ of rice or wheat/month at a reduced rate.

- Open Market Sales: Rice made available to rural and urban areas. Anyone can buy a maximum of $5 \mathrm{~kg}$ of subsidized rice each day. The program was established in response to the 2008 crisis.

\section{Key Issues for Food Crisis Preparedness}

- Bangladesh's SSN programs have a documented record of shielding the poor from destitution but are predominantly active in rural areas. Current programs spend over $2.8 \%$ of GDP (FY09) and reach approximately 4-5 $\mathrm{M}$ beneficiaries (15 \% in rural and $5 \%$ in urban areas).

- Programs provide very small benefits in the form of food/in-kind transfers, cash, or a combination of the two which could be scaled up to respond to crisis. $T$ he country has started a significant process to enhance decentralized service delivery social accountability. Bangladesh is also aligning itself to promote more efficient response during crisis in particular through the strengthening of results based Monitoring and Evaluation (M\&E).

\footnotetext{
${ }^{1}$ Draws on Barrientos et al (2010)
}

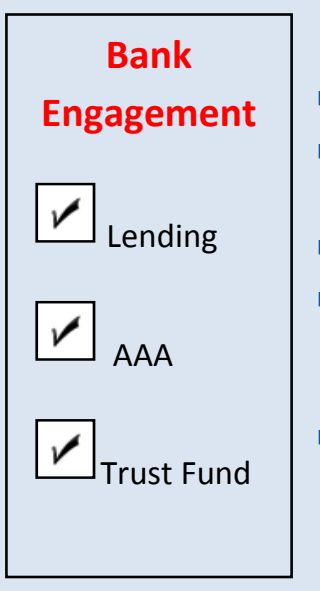

\section{Background Statistics}

- GDP per capita US\$ 551 (2009)

- Population 162.2 million inhabitants (2009)

- Poverty rate $40 \%$ (2005)

- Malnutrition height for age $43.2 \%$ and weight for age $41.3 \%$ of children under 5 (2007)

- Fiscal balance \% of GDP $-3.0 \%$ (2009 Est.); $-3.4 \%$ (2010 projection)

Source: WDI and IMF Article IV Consultations
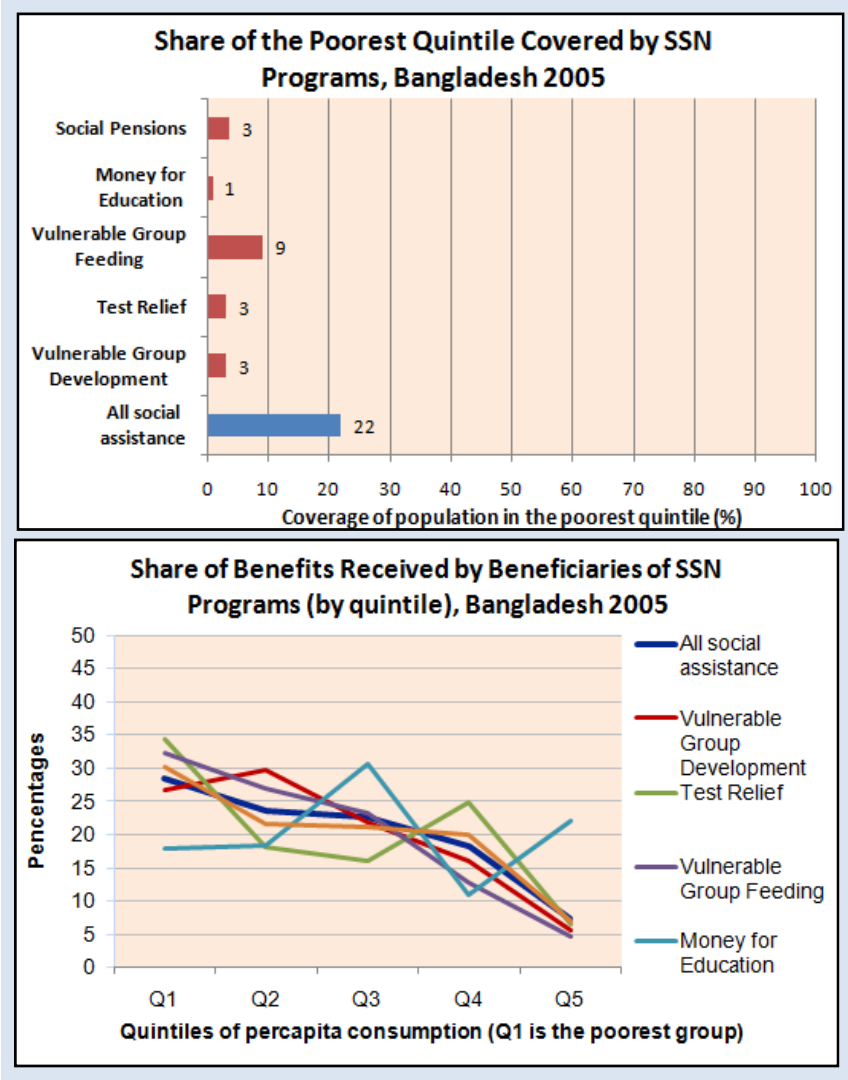

Benefits as Share of Household's Base Consumption in the Poorest Quintile, Bangladesh 2005

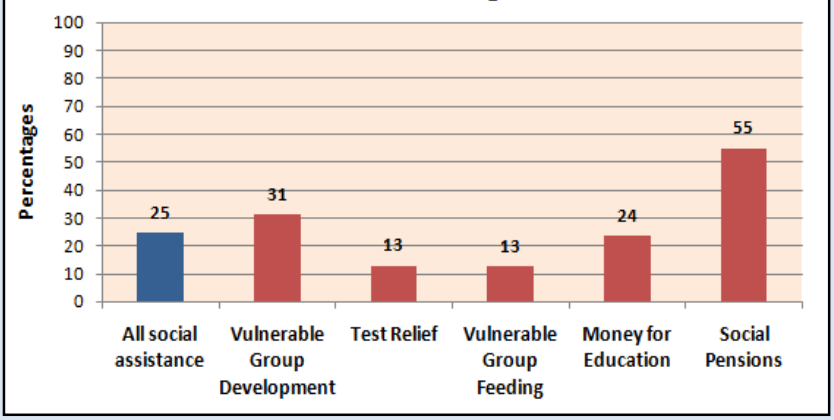

Source: World Bank Social Protection Atlas (Based on Country Household Surveys) 


\section{Food Price Increase and Safety Net Readiness: Democratic Republic of the Congo}

\section{Main safety net interventions}

- DRC Emergency Social Action Project (\$60 million) and its Additional Financing $(\$ 35 \mathrm{M})$ : The project supports the construction and rehabilitation of community-based infrastructure to improve access to social services. It has completed 581 subprojects and 66 sub-projects are ongoing benefiting a total of 647 communities. In addition, \$5 $\mathrm{M}$ from the Additional Financing targets labor-intensive PWP projects and is expected to create a total of 290,000 person/days of salaried employment targeting artisanal and unemployed miners in the Katanga province.

- The DRC Street Children Project (\$10M) - Bank-funded lending expected to become effective by end February 2011. Aims to improve the delivery of prevention and support improved services for 8,000 street children, primarily in Kinshasa. In addition, several child protection actors, including relevant Ministries, non governmental and faith based organizations will benefit from capacity building.

- RSR Pilot CCT and In-Kind Transfer Project (\$2 M): Will enhance the Government's crisis response through testing CCTs and in-kind transfers to schools and to vulnerable families to (i) prevent children at risk for dropping-out of school and (ii) support street children to return to school. It will also provide Technical Assistance (TA) and capacity building to enhance capacity to respond to future shocks.

\section{Key Issues for Food Crisis Preparedness}

- Few programs, fragmented coverage and fragile context hamper SP responses to food crisis

\section{Background Statistics}

- GDP per capita US\$160 (2009)

- Population 66 million inhabitants (2009)

- Poverty rate $71.3 \%$ (2005)

- Malnutrition height for age $45.8 \%$ and weight for age $28.2 \%$ of children under 5 (2007)

- Fiscal balance \% of GDP $-4.8 \%$ (2009 Est.); $-12.7 \%$ (2010 projection)

Source: WDI and IMF Article IV Consultations

\section{Bank Engagement}

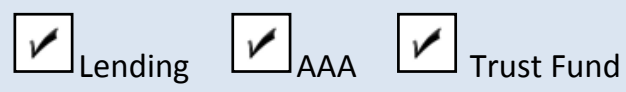




\section{Main safety net interventions}

Main focus of safety nets is protection against poverty in old-age and targeted assistance to the poor and vulnerable population.

\section{- Targeted Social Assistance (TSA) Program:}

- A means tested cash benefit (GEL 24-30 per person) distributed monthly is aimed at very poor families.

o Introduced in 2006, it has become the most important program in terms of resources (cost $0.8 \%$ of GDP in 2010) and poverty impact reaching about 400,000 people ( $10 \%$ of the population).

0 It counts on an automated MIS comprising a database of poor and vulnerable people containing $40 \%$ of household in Georgia, which is also used to target other programs such as medical insurance.

o The Government increased coverage and amount of TSA benefits in 2009 and is currently supporting the adjustment of the proxy-means testing formula, improving business processes, and restarting recertification of beneficiaries.

- Old-age state pension program:

o Provides assistance to formal and informal sector workers since eligibility is conditioned upon reaching a certain age irrespective of working history, and to internally displaced persons.

- About 850,000 people (around $20 \%$ of population) between women above 60 and men above 65 , including disabled and survivors, receive a basic pension amounting to about GEL 70 per month or approximately $15 \%$ of the average wage in 2008 .

\section{Key Issues for Food Crisis Preparedness}

- The Government has already reacted to the food crisis by announcing a one-time GEL 30 food vouchers to all 1 million households (i.e. completely untargeted) as of March $10^{\text {th }}$ running until middle of April.

- TSA program responded well to the food, fuel and financial crisis increasing its beneficiaries robustly through 2009.

- Overall high allocation of $1.5 \%$ and $4.5 \%$ of GDP to finance safety nets programs and pensions respectively It is estimated that in 2009 poverty would have been 7 percent higher $(25.7 \%)$ without TSA and 52 percent higher (39.1\% vs. $25.7 \%$ ) without pensions.

- The Government is planning to take steps to further improve TSA administration processes through integrated IT systems with a focus on a client-friendly, one-stop ship approach to operating local State Social Service Agency offices.

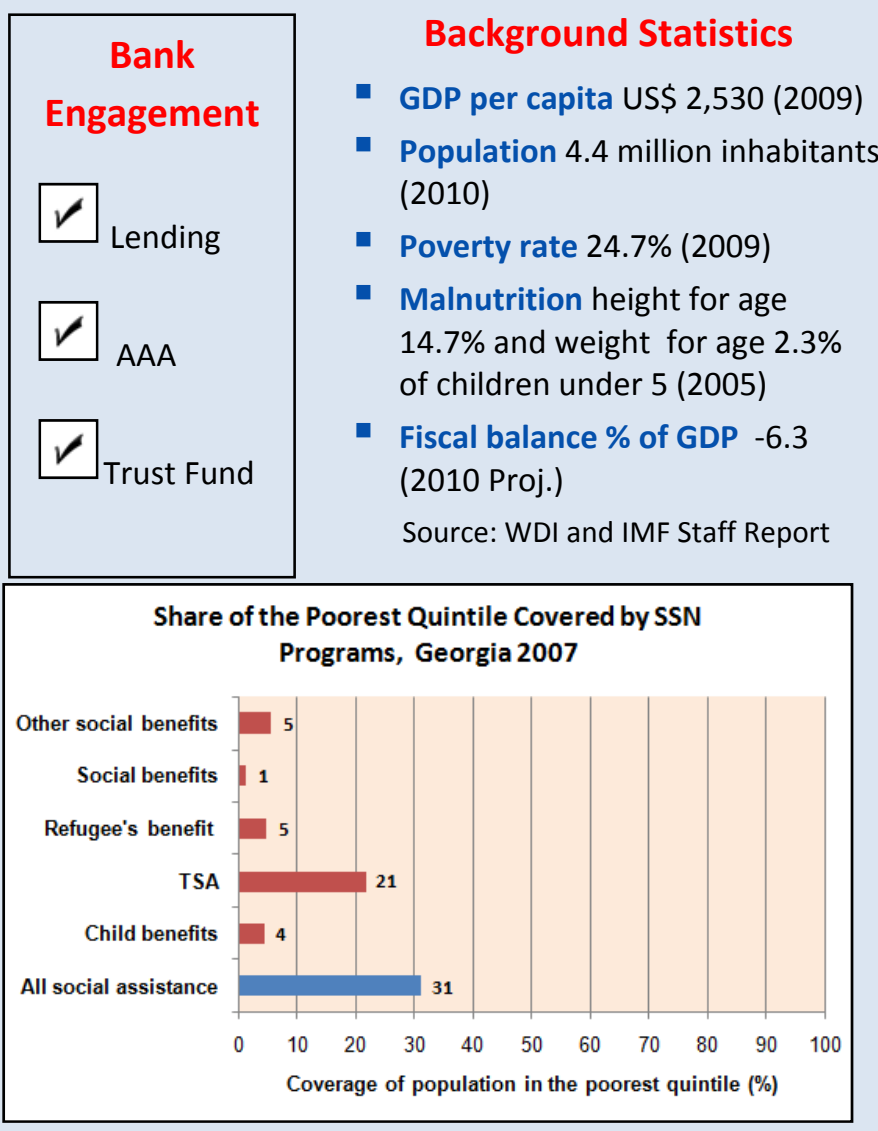

Share of Benefits Received by Beneficiaries of SSN Programs (by quintile), Georgia 2007

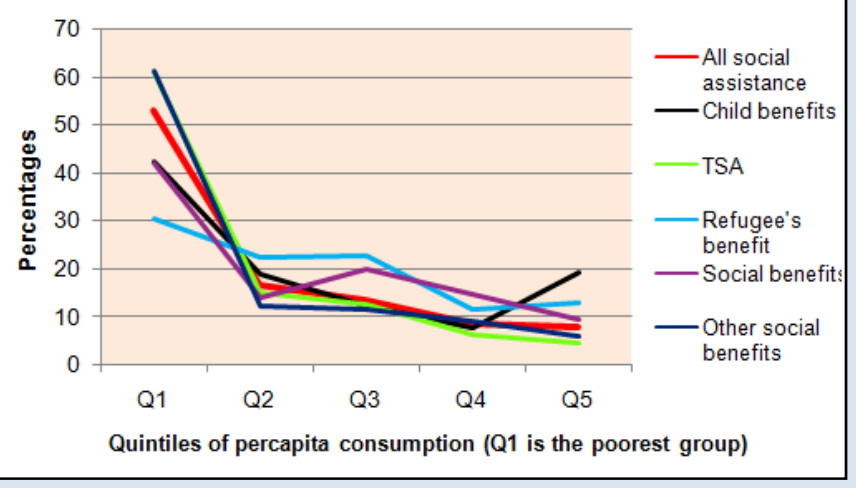

Benefits as Share of Household's Base Consumption in the Poorest Quintile, Georgia 2007

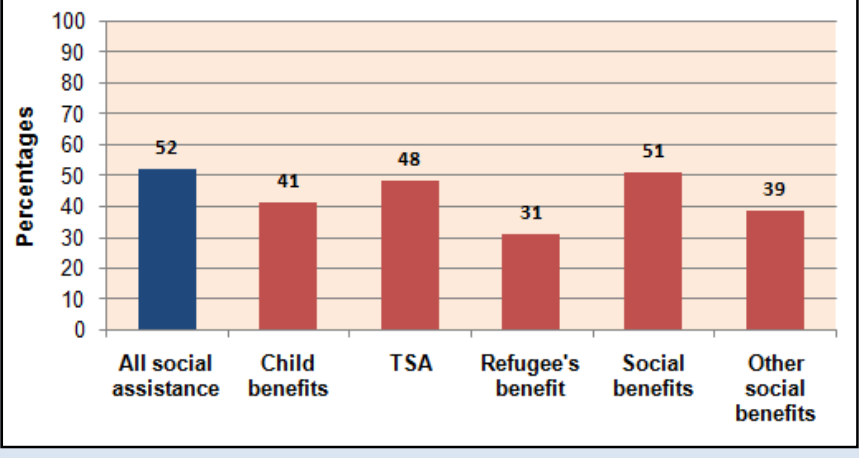

Source: World Bank Social Protection Atlas (Based on Country Household Surveys) 


\section{Food Price Increase and Safety Net Readiness: Guatemala}

\section{Main safety net interventions}

\section{Mi Familia Progresa (CCT) - Bank-funded}

- Provides income payments to poor mothers in rural areas on the condition that they send their children to school and for health check-ups.

- The program started in April 2008 and expanded very rapidly. It now covers over 900,000 families (60\% more than 2009) and over $2.5 \mathrm{M}$ children. In 2010 the program cost $0.34 \%$ of GDP.

- In 2010 the program improved transparency and the verification of compliance of health and education and is looking to improve efficiency and effectiveness, evaluate its processes, strengthen management capacity at national and local level, and improve the program in all its business processes.

- The Bank approved a loan to support the Government of Guatemala to expand basic services of health and education and rural infrastructure but it is still pending Congress approval.

\section{Key Issues for Food Crisis Preparedness}

- The CCT program and its Proxy-Means Test (PMT) targeting method may represent an important mechanism in reaching the poorest households in the country. However, this would leave out the urban poor who might be hit significantly by increases in food prices and who cannot resort to own production.

- In Guatemala City the government has a program called Comedores Solidarios that provides shelters where meals and drinks are given. This may be used to provide food to urban poor. However, the targeting performance and the capacity of the program to expand in response to a crisis are uncertain.

- Government initiated in 2010 the development of an Integrated Beneficiary Registry of social protection (SP) which aims to improve the targeting and selection of beneficiaries of SP programs like scholarships, transfers in kind, etc.

\section{Background Statistics}

- GDP per capita US\$2,661 (2009)

- Population 14 million inhabitants (2009)

- Poverty rate $51.0 \%$ (2006)

- Malnutrition height for age $54.3 \%$ and weight for age $17.7 \%$ of children under 5 (2002)

- Fiscal balance \% of GDP -1.6 (2008); $-3.1 \%$ (2010 projection)

Source: WDI and IMF Article IV Consultations

\section{Bank Engagement}

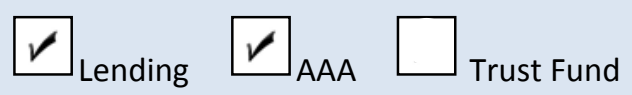




\section{Main safety net interventions}

- A range of safety net operations have been established by Government and donor partners, especially in the areas of school feeding, labor intensive public works and nutrition.

- Support to ongoing reforms and poverty reduction: Increasing expenditures on social assistance, directly through school feeding programs, mother-child programs, and labor intensive public works; and indirectly through subsidies on food commodities. In 2008, GFRP financing used to safeguarding the Government's ongoing reform and poverty reduction program by helping to partially fill the unanticipated financing gap created by the food price crisis. In 2009, RSR funding ( $\$ 3$ million) to support basis health, education and nutrition needs. In

- Post earthquake recovery and rehabilitation: Creating opportunities for the poor and vulnerable to earn an income to meet their basic and urgent needs, while rehabilitating basic infrastructure and services (remove rubble, clean street, clear drains, collect waste and restore water supplies); Targets the poor and vulnerable people living in Port au Prince and in a few key areas such as Gonnaives and St Marc where displaced persons have been housed temporarily. Including World Bank JSDF - Community Cash for Work Project (\$3 M) 2010; as well as Education for All - Additional Grant to increase coverage of school feeding and access to schooling through tuition waivers.

- Note: A variety of safety net programs are carried out by partners, some in collaboration with the World Bank. For example WFP is currently supporting almost 2 million beneficiaries through school feeding, cash for works and nutrition.

\section{Key Issues for Food Crisis Preparedness}

- No specific policy or program has been put in place to respond to the current crisis but the government maintains certain policies and programs implemented after the earthquake that might be useful e.g. cash and in-kind transfers. Rising food prices threaten to unravel some of the progress in building capacity and response in aftermath of January 2010 earthquake, with the potential to cause social unrest.

- A number of safety nets programs have been developed by Government, donors, and NGOs but funding and coverage are limited and does not cover neediest. Administration capacity is weak and fragmentation is notable. The Ministry with the mandate for safety nets is grossly underfunded ( $1 \%$ of total internal budget) and under-staffed. Some

- Poverty targeting is a challenge given deficiencies in the quality of information of food prices, price transmission, food stocks and policy responses.

- Although remittances are partly considered the most important safety net programs, it is important to highlight that they tend to exclude the poorest that are living in rural areas. 


\section{Main safety net interventions}

India has a well-developed safety net, including a mix of central and state government policies and programs.

- Mahatma Gandhi National Rural Employment Guarantee (MGNREG): Guarantees 100 days of work per rural households per year and setting state-specific agricultural minimum wages to engage in manual public works. The scheme, the largest public works program in the world, provided employment to 44 million rural households in 2010/11, budgeted at nearly $\$ 9$ billion $(0.6 \%$ of GDP).

- The subsidized Public (food) Distribution System (PDS): Provides subsidized wheat and rice, plus kerosene and sugar in most states distributed through Fair Price Shops to those below the poverty line (BPL) and a smaller entitlement to those above poverty line $(\mathrm{APL})$. It is the largest system in the world, covering over 65 million households at a cost of $0.7 \%$ GDP.

- Indira Gandhi National Old Age Pension Scheme (IGNOAPS): Monthly cash benefits provided to below poverty line (BPL) elderly, frequently topped up by state funds. The program covers about 16 million elderly ( $\$ 1.1$ billion budgeted in 2010). Annapurna supplements the main old age scheme, providing 10 $\mathrm{kgs}$ of food grains free to the destitute elderly eligible for IGNOAPS but not receiving benefits.

- Midday Meals: Hot meals for children grades 1-8 in government and government-aided schools. The program reaches about 120 $\mathrm{M}$ children with a budgeted expenditure of \$2.1 billion in 2010 .

\section{Key Issues for Food Crisis Preparedness}

- Spending on safety nets has increased in recent years, most prominently through MGNREG.

- The large number of programs creates a variety of avenues for responding to a crisis but is administratively challenging with responsibilities and funding shared across the states and the central government.

- PDS has wide coverage but exhibits extensive leakage and administrative waste as currently implemented. The program may be reformed under the Food Security Act being discussed.

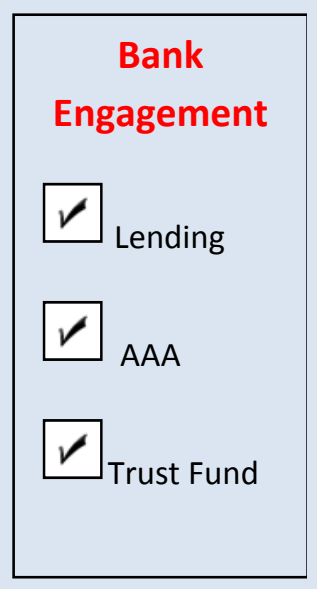

Background Statistics

- GDP per capita US\$1,124(2010)

- Population 1.2 billion inhabitants (2010)

- Poverty rate $27.5 \%$ (2005)

- Malnutrition height for age $47.9 \%$ and weight for age $43.5 \%$ of children under 5 (2006)

- Fiscal balance \% of GDP $-6.8 \%$ (2009 Est.); -6.6 \% (2010 Proj.) Source: WDI and IMF Article IV Consultations
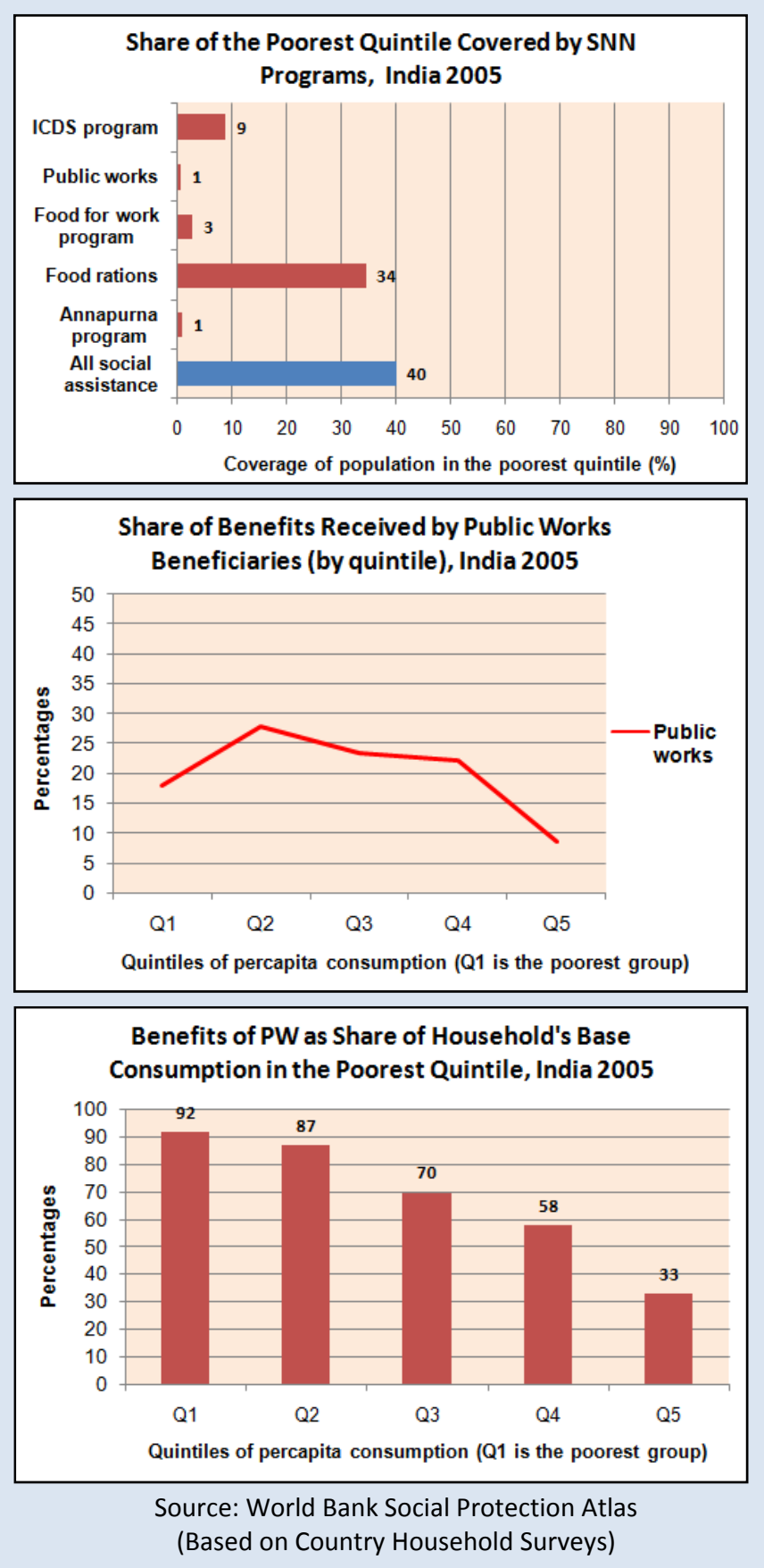


\section{Main current safety net interventions}

- Beras untuk rumah tanggah Miskin (Raskin) - Subsidized Rice transfer (largest SSN in terms of spending):

o Monthly allocations of subsidized rice to distribution points where households $(\mathrm{HH})$ can buy $10-20 \mathrm{~kg}$ at below-market prices. Targeting 17.5 Million (M) HH in 2011.

- Jaminan Kesehatan Masyarakat (Jamkesmas) - Fee Waivers for Health Services (health card):

o Free outpatient services at regional health posts and nearly unlimited inpatient services at public hospitals;

o $16 \mathrm{M}$ beneficiaries added in 2008 totaling $72 \mathrm{M}$ or $1 / 3$ of the population. However, on average only $44 \%$ of cardholders use the services and utilization rates are higher among richer $\mathrm{HH}$.

- Program Keluarga Harapan (PKH) - CCT pilot (Launched in 2007 and planned to run until 2015):

o PKH Payments to poor $\mathrm{HH}$ with a pregnant or lactating mother or one or more 0 to 5 year olds or school-aged children. Current coverage across 13 / 33 provinces at 820,000 very poor $\mathrm{HH}$ with an ultimate goal to reach national coverage and 2.0 million $\mathrm{HH}$ by 2015 or earlier;

o Slowly improved operation and administration. MIS and the verification systems necessary for enforcing compliance with conditionalities are now fully operational.

Other Programs with a safety net component (i) Program Nasional Pemberdayaan Masyarakat (PNPM) -Community Driven Development Schemes: Block grants to communities principally for local infrastructure conditional on completion of community meeting to collectively choose projects. During recent episodes of disaster in volcano- and earthquake-prone areas, funds were made available for disaster relief and (ii) Bantuan Operasi Sekolah (BOS) - Direct Grants to Schools: Launched in 2005 using some savings from fuel subsidy cuts and (iii) Fuel and Electricity price subsidies.

- Bantuan Langsung Tunai (BLT): Since 2005 a temporary unconditional cash transfer program has been introduced twice, in order to offset the effects of fuel subsidy reform (2005/06) and to offset the effects of further fuel subsidy reform as well as respond to the food price crisis and trailing global financial crisis (2008/09). It benefited about a third of the population. No permanent administrative apparatus or funds, and no permanent program structures or personnel, were put in place.

\section{Key Issues for Food Crisis Preparedness}

- Domestic price of rice: Currently, $35 \%$ above comparable international price. Rice constitutes nearly $25 \%$ of poor HH's spending. For every 1 poor $\mathrm{HH}$ that benefits from higher rice prices, there are 3 who are net consumers of rice and are harmed. A $10 \%$ increase is estimated to lead to a $1.3 \%$ point increase in poverty. In response to the current crisis the GOI has allocated additional resources for Reskin Program to cover the growing cost of the subsidy. The GOI is also considering plans to further increase the amount of rice available later in 2011.

- Fiscal position: With low budget deficits (estimated at $0.6 \%$ of GDP in 2010 and budgeted to be $1.8 \%$ of GDP in 2011 ), Indonesia can afford to respond to the current food crisis with existing SSN. Fiscal position would be further enhanced if it reallocated spending away from costly and regressive energy subsidies.

- GOI has made progress towards unifying SSN programs, including reform plans underway in the following areas: i) improvement in the design of Jamkesmas, ii) improvements in the implementation of PKH and iii) M\&E system and 4) the establishment of a HH targeting system. 


\section{Main safety net interventions}

\section{Unified Monthly Benefit (UMB):}

- Integrated cash transfer system which targets poor families with children, which is fairly strong in channeling benefits to the poor as the poorest $40 \%$ the population receive more than $77 \%$ of total benefits paid out. While coverage is low (approx.9\% of population and $20 \%$ of the poorest quintile of the population), UMB has been instrumental in reducing the extreme poverty gap by $12 \%$.

- Was platform for crisis response in 2008, when Bank provided funding to top up benefits temporarily $\$ 4.5 \mathrm{M}$ were allocated to finance the top-up, each in the amount of KGS 35 per capita (20\% increase to the average UMB amount received). From 2009, the top-up was increased to KGS 40 and taken over by GOK (using EC funds) as a proven efficient practice of transferring benefits to the poor.

\section{Nutrition response in 2008 (also funded by GFRP IDA loan):}

- Vitamin A supplements provided to around 154,000 postpartum women and 550,000 children under age 5. Education material on nutrition in Kyrgyz Republic and Russian was used for training on three modules: breastfeeding, nutrition of mothers, and complementary feeding.

\section{Key Issues for Food Crisis Preparedness}

- The government has an overall strategy for SP and a mixed set of SSN programs. But the majority of these programs remain categorical and take no account of beneficiaries' welfare. Povertytargeted benefits still remain low and/or targeting uneven. Also, improvement of coverage and benefit administration while adhering to strong targeting is crucial for maintaining UMB as the instrument for crisis preparedness/response.

- In 2010 the GOK implemented a wide-scale reform of in-kind categorical benefits to be replaced by cash transfers. Cash compensations represent the GOK actions to improve transparency, simplify administration and expand consumer coverage. But reforms are not fully completed as cash benefits remain rights-based rather than means-tested.

- The UMB experience represents a very effective vehicle to leverage SSN to scale up benefits, expand coverage quickly and respond to crisis. Administration is simple, transparent and conducive to low costs, and low inclusion errors.

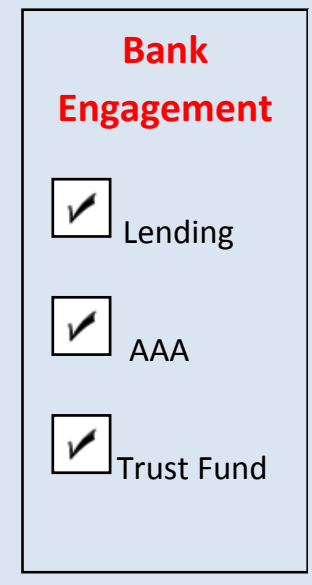

\section{Background Statistics}

- GDP per capita US\$ 860 (2009)

- Population 5.3 million inhabitants (2009)

- Poverty rate $31.7 \%$ (2008)

- Malnutrition height for age $18.1 \%$ and weight for age $2.7 \%$ of children under 5 (2008)

- Fiscal balance \% of GDP -1.9 (2009 Prel); -4.5\% (2010 projection)

Source: WDI and IMF Article IV Consultations

Share of the Poorest Quintile Covered by SSN Programs, Kyrgyz Republic 2006

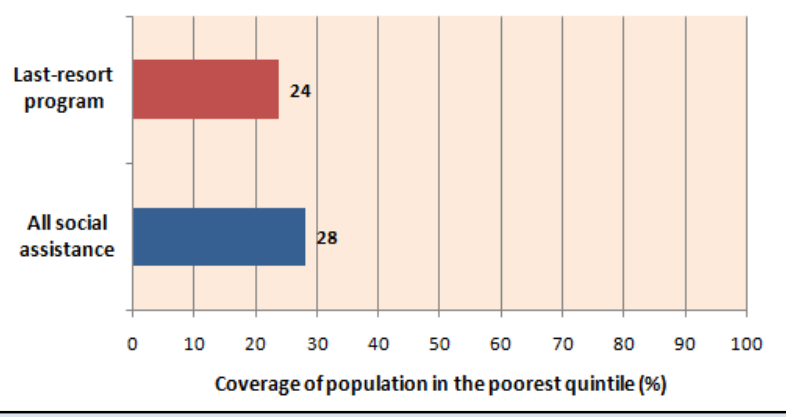

Share of Benefits Received by Beneficiaries of SSN Programs (by quintile), Kyrgyz Republic 2006

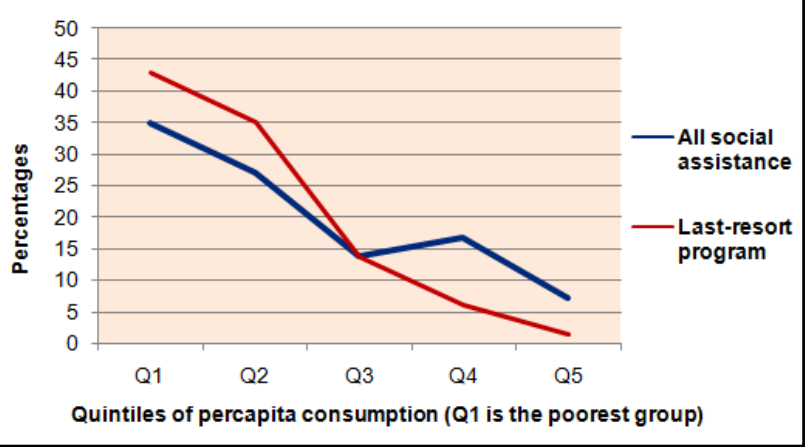

Benefits as Share of Household's Base Consumption in the Poorest Quintile, Kyrgyz Republic 2006

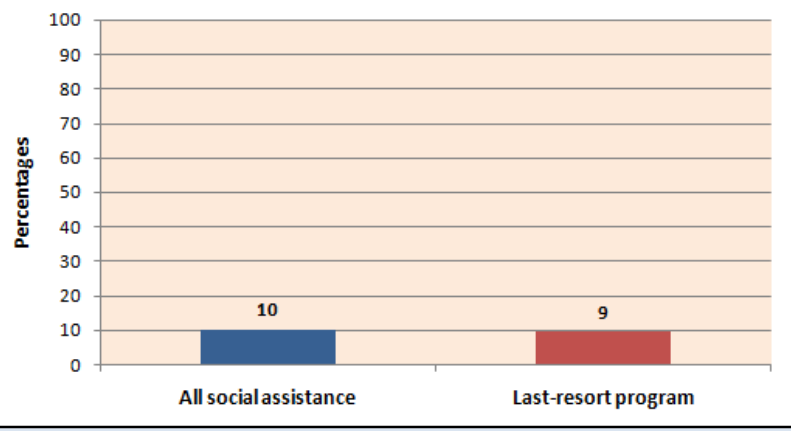

Source: World Bank Social Protection Atlas (Based on Country Household Surveys) 


\section{Main current safety net interventions}

- Food Stamp Program (FSP): Created to provide cash during 2008 food crisis for categorical groups e.g. pensions, disabled. Now, being used to distribute monthly food stamps to the poorest 100,000 or $5 \%$ households $(\mathrm{HH})$ in 1 out of 9 districts and 4 states identified though a PMT system. The program is supported by ADB.

- Medicard program: Improve health care access of poor HH affected by global financial crisis.

- Bank-funded DPC 2 (\$6.53 M) 2010 and Multi-Sectoral TA - Reform of Mongolia's system of social transfers: i) Consolidation, rationalization, and simplification of the system of social transfers; ii) establishment of a new targeting mechanism for identifying the poor, based on a PMT; and iii) introduction of a new benefit/transfer, targeted exclusively to poor $\mathrm{HH}$. The TA seeks to strengthen the capacity of the ministry of social welfare and labor. Approved and recently endorsed by the Government to support welfare reform law. Law is still pending Parliament approval.

- Child Money Program (CMP): Until early 2010, a quasi-universal program paid $\$ 117$ per child/year to HH with children under 18 on the condition they lived with their parents or guardians and were enrolled in school. It was discontinued with the advent of the HDF.

- Human Development Fund (HDF) was created after the 2008 electoral campaign promises by both main political parties to redistribute Mongolia's mineral wealth equitably. According to the Law, HDF can be used for (i) pension and health insurance premiums; (ii) housing purchases; (iii) cash benefits; and (iv) education and health services). The cash benefits currently paid each month are Mongolian Tugrik of 20,000 (about \$15) per person.

- Community-led infrastructure development for the urban poor in Ulaanbaatar (JSDF TF\$ 3M): Seeks to enable the most vulnerable urban poor to earn additional income to compensate for high food costs and high unemployment through work on community infrastructure, sanitation, and recreation and at the same time develop useful vocational skills.

\section{Key Issues for Food Crisis Preparedness}

- In general, social welfare system provides a large number of fragmented, small benefits to categorically targeted groups.

- Mongolia welfare system currently does not have poverty targeted benefit. Such support for poor has been planned under the draft Social Welfare Law revision. The Law includes provision such as introduction of Poverty Targeted Benefit and consolidation of categorical benefits.

- Simulation analysis suggests that a new poverty-targeted benefit would increase per capita consumption among the poor and reduce poverty in Mongolia more at significantly lower cost than Mongolia's largest former universal transfer program, The Child Money Program. ${ }^{13}$

\footnotetext{
${ }^{13}$ Findings based on simulation analysis carried out on Mongolia's 2007/08 household survey, the HIES/LSMS, as part of ongoing World Bank technical assistance to the Ministry of Social Welfare and Labor.
} 


\section{Food Price Increase and Safety Net Readiness:}

Pakistan

\section{Main current safety net interventions}

- Benazir Income Support Program (BISP): Established as flagship SSN program in 2009/10. 2.2 million female headed families received cash transfer benefits in the first 10 months of operation. Over the next 5 years the program aims to reach $40 \%$ of those living below poverty line, or $15 \%$ of population.

- Zakat system: $60 \%$ is used for Guzara Allowance (Monthly payments of PKR 500 to poor $\mathrm{HH}$ ). The remaining is divided in i) education stipends paid to pupils/students from primary to university level; ii) health stipends to be used in government facilities; iii) marriage grants to unmarried women; transfers to needy $\mathrm{HH}$ in emergency/disaster situations.

- CCT Child Support Program (CSP): Families with 1 school-going child are paid PKR 300/month and those with more than 1 receive PKR 600/month. Results suggest that compliance rate is good and drop-out rates low. Piloted in 11 districts and now being expanded to 8 districts.

\section{Background Statistics}

- GDP per capita US\$ 955 (2009)

- Population 169.7 million inhabitants (2009)

- Poverty rate $32.6 \%$ (1999)

- Malnutrition height for age $41.5 \%$ and weight for age $31.3 \%$ of children under 5 (2001)

- Fiscal balance \% of GDP -5.0 (2008 Est.); $-3.8 \%$ (2010 projection)

Source: WDI and IMF Article IV Consultations

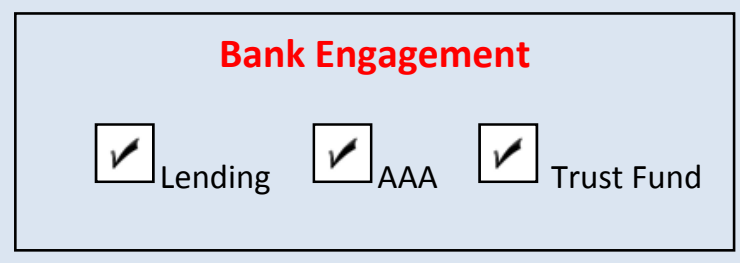

- Khyber Pakhtunkhwa Province (KP) and the Federally Administered Tribal Areas (FATA) Emergency Recovery Project: Provide and expand UCT and CCT to HH affected by the militancy and flood in the target areas.

- Citizen Damage Compensation Program: The transfer was initially set at PKR 20,000. The transfer will increase to KR 40,000 in coming months for those whose homes were partially destroyed by the floods and to KR 80,000 for those whose homes were totally destroyed.

- Bank-funded DPC 2009: To establish national targeting system, strengthen institutional framework for SSN, and improve governance/policy.

- Bank-funded AAA:

o CSP received TA from the Bank to set up pilot and carry out its evaluation.

o Analytical work to assess and advise on the design parameters of Pakistan's SSN programs.

\section{Key Issues for Food Crisis Preparedness}

- In last two years under BISP, Pakistan has been strengthening administrative and technical capacity considerably in order to protect against future adverse economic or agro-climatic shocks.

- Major efforts are ongoing to enhance the operation and management (targeting, communications strategy, beneficiary outreach, etc) of a nationwide, effective and transparent SSN system.

- Pakistan has more than double its SSN spending to GDP ratio from $0.4 \%$ to close to $1.0 \%$. 


\section{Food Price Increase and Safety Net Readiness:}

Tajikistan

\section{Main safety net interventions}

- Electricity and gas compensation: In 2009, the Government budgeted about \$5 Million (M) for electricity and gas compensation. At least half of the budget for the electricity and gas program was used to purchase and distribute energy-saving light bulbs. Program requires payment of benefits to reach 18 to $20 \%$ of the population.

- Conditional cash payment (CCP) - CCT: Established in 2000, the program pays less than $\$ 10$ per year - equivalent to about $30 \%$ of annual direct schooling expenditures by a family - to selected families of poor children from grades 1 through 9 on the condition that they enroll in and attend school. The size of the benefit is considered negligible and potentially too low to influence school attendance.

- The Government has also budgeted about \$1 M in aid to returnees and migrants from dangerous zones and there are several very small programs including a recent pilot of poverty-targeted social assistance in two districts.

- GFRP - FPCR: \$4 M in additional financing to support nutritional supplementation and nutrition education, and to improve the monitoring of children under 5 . So far nutritional training reached 170,000 pregnant and lactating women, and 50,000 women were given nutritional supplements. Moreover, 1,200 primary care facilities received weighing equipment and nutrition training has been delivered to 432 doctors and nurses.

- Pilot Nutrition Investments (JSDF \$3 M approved on June 2011). This grant would address the shockingly high malnutrition rates among infants and young children in severely food insecure districts of Khatlon province.

- RSR pilot (January 2011 - $\$ 2.5 \mathrm{M})$ : Target benefits to the poor more accurately to protect them more effectively in times of crisis and beyond. It will serve as a credible vehicle through which donors could channel additional benefits by helping the GOT roll-out national reform.

- Bank ESW: Along with the EU, Bank supports the GOT's sector reform of delivering social assistance.

IDA Pipeline: Preparing a US\$ 3 M IDA grant that will support a registry of social assistance and capacity building.

\section{Key Issues for Food Crisis Preparedness}

- During the 2008 food crisis, Tajikistan did not operate an effective SSN that could be leveraged to protect the poor. None of the existing programs was well-targeted or could trace distribution of benefits. Lack of a functional system presented an additional challenge for the GFRP response.

- The existing programs are small in coverage and benefit levels - only $23 \%$ of social assistance is received by the poorest $20 \%$ of the population and social assistance as a \% of GDP is the smallest in the ECA region $-0.2 \%$.

- Tajikistan is in process of consolidating its main programs and replacing them with a single targeted social assistance program. This reform will improve the administration and management of social assistance, in particular through establishing an improved MIS, including an electronic registry. 


\section{Annex 3 \\ Food and Fuel Crisis Response \\ Funding from GFRP, RSR and JSDF Programs \\ 2008-2011}


Finance, Food and Fuel Crisis Response: GFRP, RSR and JSDF Programs 2008-2011 (As of July 26, 2011)

\begin{tabular}{|c|c|c|c|c|c|c|c|c|c|c|c|c|c|}
\hline \multirow[b]{2}{*}{ No. } & \multirow[b]{2}{*}{ Country } & \multirow[b]{2}{*}{$\begin{array}{c}\# \text { of } \\
\text { Projects }\end{array}$} & \multirow[b]{2}{*}{$\begin{array}{l}\text { Project } \\
\text { Duration }\end{array}$} & \multirow{2}{*}{$\begin{array}{c}\text { Grant } \\
\text { In US\$ } \\
\text { Million }\end{array}$} & \multirow{2}{*}{$\begin{array}{c}\text { TOTAL SSN } \\
\text { Component } \\
\text { US \$ } \\
\text { Million }\end{array}$} & \multicolumn{4}{|c|}{ Type of Intervention } & \multicolumn{4}{|c|}{ Funding Source } \\
\hline & & & & & & $\begin{array}{c}\text { Direct } \\
\text { Transfers }\end{array}$ & $\begin{array}{l}\text { Indirect } \\
\text { Transfers }\end{array}$ & Nutrition & TA/Capacity & GFRP TF & $\begin{array}{l}\text { GFRP } \\
\text { IDA }\end{array}$ & RSR & JSDF \\
\hline
\end{tabular}

\section{Africa}

\begin{tabular}{|c|c|c|c|c|c|c|c|c|c|c|c|c|c|}
\hline 1 & Burkina Faso & 1 & 4/2010-6/2011 & 0.5 & 0.5 & v & & & & & & $\sqrt{ }$ & \\
\hline 2 & Burundi & 1 & 08/2008-07/2009 & 10 & 10 & V & $\mathbf{v}$ & & & $\sqrt{ }$ & & & \\
\hline 3 & Cameroon & 1 & 4/2010-6/2011 & 0.5 & 0.5 & $\mathbf{v}$ & & & & & & $\sqrt{ }$ & \\
\hline 4 & $\begin{array}{l}\text { Central } \\
\text { African } \\
\text { Republic }\end{array}$ & 1 & $08 / 2008-02 / 2012$ & 7 & 3.25 & $\sqrt{ }$ & & & $\mathbf{V}$ & $\sqrt{ }$ & & & \\
\hline \multirow{2}{*}{5} & \multirow{2}{*}{ Comoros } & \multirow{2}{*}{2} & $6 / 2010-7 / 2014$ & 2.3 & 2.6 & $\mathbf{v}$ & & & & & & & $\mathbf{v}$ \\
\hline & & & 07/2009 - & 1 & 1 & $\mathbf{V}$ & & & & $\begin{array}{lll} & \end{array}$ & & & \\
\hline \multirow[t]{2}{*}{6} & DRC & 1 & Not effective & 2 & 2 & V & & & $\mathbf{v}$ & & & $\sqrt{ }$ & \\
\hline & $\begin{array}{l}\text { DRC (and } \\
\text { Rwanda) }\end{array}$ & 1 & $2 / 2010-6 / 2011$ & 0.07 & 0.07 & & & & $\mathbf{V}$ & & & $\sqrt{ }$ & \\
\hline \multirow{2}{*}{7} & \multirow{2}{*}{ Ethiopia } & \multirow{2}{*}{2} & $12 / 2008-07 / 2010$ & 275 & 25 & V & & & & & v & & \\
\hline & & & $12 / 2010-9 / 2012$ & 0.95 & 0.95 & & & & $\mathbf{V}$ & & & $\mathbf{v}$ & \\
\hline 8 & Gambia & 1 & $12 / 2010-12 / 2012$ & 3 & 3 & & & $\mathbf{v}$ & $\mathbf{V}$ & & & $\mathbf{v}$ & \\
\hline 9 & Ghana & 1 & $4 / 2010-6 / 2011$ & 0.1 & 0.1 & & & & $\mathbf{V}$ & & & $\mathbf{v}$ & \\
\hline \multirow{2}{*}{10} & \multirow{2}{*}{ Guinea } & \multirow{2}{*}{1} & 09/2008-07/2009 & 10 & 2.5 & \multirow[t]{2}{*}{$\mathbf{V}$} & & & \multirow[b]{2}{*}{$\mathbf{v}$} & \multirow[t]{2}{*}{$\sqrt{ }$} & & \multirow[b]{2}{*}{$\mathbf{v}$} & \\
\hline & & & 07/2011-09/2012 & 0.4 & 0.4 & & & & & & & & \\
\hline 11 & $\begin{array}{c}\text { Guinea } \\
\text { Bissau }\end{array}$ & 1 & $08 / 2008-08 / 2011$ & 5 & 1.5 & $\mathbf{v}$ & & & & $\mathbf{v}$ & & & \\
\hline \multirow{3}{*}{12} & \multirow{3}{*}{ Kenya } & \multirow{3}{*}{3} & $4 / 2010-12 / 2012$ & 1.3 & 1.3 & & & & $\mathbf{V}$ & & & $\sqrt{ }$ & \\
\hline & & & $3 / 2009$ - & 50 & 40 & $\sqrt{ }$ & & & & & $\sqrt{ }$ & & \\
\hline & & & $5 / 2010-6 / 2011$ & 1.5 & 1.5 & & & & V & & & $\sqrt{ }$ & \\
\hline 13 & Lesotho & 1 & $4 / 2010-12 / 2012$ & 0.23 & 0.23 & & & & $\sqrt{ }$ & & & $\sqrt{ }$ & \\
\hline \multirow{2}{*}{14} & \multirow{2}{*}{ Liberia } & \multirow{2}{*}{2} & $11 / 2010-12 / 2011$ & 0.29 & 0.29 & & & & V & & & $\sqrt{ }$ & \\
\hline & & & $05 / 2008-06 / 2012$ & 10 & 7 & $\mathbf{V}$ & & $\mathbf{v}$ & & v & & & \\
\hline \multirow{2}{*}{15} & \multirow{2}{*}{ Madagascar } & \multirow{2}{*}{2} & $08 / 2008-12 / 2011$ & 10 & 10 & V & $\mathbf{v}$ & & & $\sqrt{ }$ & & & \\
\hline & & & $12 / 2008-12 / 2011$ & 40 & 12 & $\mathbf{v}$ & & & & & V & & \\
\hline
\end{tabular}




\begin{tabular}{|c|c|c|c|c|c|c|c|c|c|c|c|c|c|}
\hline \multirow[b]{2}{*}{ No. } & \multirow[b]{2}{*}{ Country } & \multirow[b]{2}{*}{$\begin{array}{c}\text { \# of } \\
\text { Projects }\end{array}$} & \multirow[b]{2}{*}{ Year } & \multirow[b]{2}{*}{ Grant } & \multirow{2}{*}{$\begin{array}{c}\text { TOTAL SSN } \\
\text { Component } \\
\text { US \$ } \\
\text { Million }\end{array}$} & \multicolumn{4}{|c|}{ Type of Intervention } & \multicolumn{4}{|c|}{ Funding Source } \\
\hline & & & & & & $\begin{array}{l}\text { Direct } \\
\text { Transfers }\end{array}$ & $\begin{array}{l}\text { Indirect } \\
\text { Transfers }\end{array}$ & Nutrition & TA/Capacity & GFRP TF & $\begin{array}{l}\text { GFRP } \\
\text { IDA }\end{array}$ & RSR & JSDF \\
\hline
\end{tabular}

\section{Africa (continuation)}

\begin{tabular}{|c|c|c|c|c|c|c|c|c|c|c|c|c|c|}
\hline & Nigeria & 1 & 07/2011-09/2012 & 0.4 & 0.16 & & & & & & & v & \\
\hline 16 & Rwanda & 1 & $1 / 2011-9 / 2012$ & 2 & 2 & & & & $\mathbf{v}$ & & & $\mathbf{v}$ & \\
\hline \multirow{2}{*}{17} & \multirow{2}{*}{ Senegal } & \multirow{2}{*}{2} & $05 / 2009-$ & 10 & 10 & $\mathbf{v}$ & & $\mathbf{v}$ & & 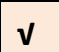 & & & \\
\hline & & & $10 / 2010-12 / 2012$ & 0.3 & 0.3 & & & & $\mathbf{v}$ & & & $\mathbf{v}$ & \\
\hline \multirow{4}{*}{18} & \multirow{4}{*}{ Sierra Leone } & \multirow{4}{*}{4} & $6 / 2010-12 / 2014$ & 2.8 & 2.8 & $\sqrt{ }$ & & $\mathbf{v}$ & & & & & $\mathbf{v}$ \\
\hline & & & $11 / 2009-12 / 2010$ & 3 & 3 & $\sqrt{ }$ & & & & $\checkmark$ & & & \\
\hline & & & $08 / 2008-12 / 2010$ & 7 & 7 & $\sqrt{ }$ & $\mathbf{v}$ & $\mathbf{v}$ & & v & & & \\
\hline & & & $07 / 2011-09 / 2012$ & .3 & .3 & & & & $\boldsymbol{v}$ & & & $\mathbf{v}$ & \\
\hline 19 & Sudan & 1 & $10 / 2008-09 / 2011$ & 5 & 1.5 & $\sqrt{ }$ & & & & v & & & \\
\hline \multirow{2}{*}{20} & \multirow{2}{*}{ Tanzania } & \multirow{2}{*}{2} & 07/2011-09/2012 & 2 & 2 & v & & & & & & $\mathbf{v}$ & \\
\hline & & & 06/2009- & 220 & 30 & $\mathbf{v}$ & & & v & & $\mathbf{v}$ & & \\
\hline \multirow{3}{*}{21} & \multirow{3}{*}{ Togo } & \multirow{3}{*}{3} & $4 / 2010-6 / 2011$ & 0.09 & 0.09 & & & & $v$ & & & $\sqrt{ }$ & \\
\hline & & & $11 / 2010-12 / 2011$ & 0.28 & 0.28 & & & & $\mathbf{v}$ & & & $\mathbf{v}$ & \\
\hline & & & $10 / 2008-N / A$ & 7 & 2 & $\boldsymbol{v}$ & & & & $v$ & & & \\
\hline
\end{tabular}

\section{East Asia \& The Pacific}

\begin{tabular}{|c|c|c|c|c|c|c|c|c|c|c|c|c|c|}
\hline 22 & Laos & 1 & $1 / 2009-12 / 2011$ & 2 & 2 & $\sqrt{ }$ & & $\mathbf{V}$ & & v & & & \\
\hline \multirow{2}{*}{23} & \multirow{2}{*}{ Mongolia } & \multirow{2}{*}{2} & 03/2011- & 2.77 & 2.77 & $\sqrt{ }$ & & & & & & & $\mathbf{v}$ \\
\hline & & & $2 / 2010-6 / 2011$ & 0.07 & 0.07 & & & & $\mathbf{V}$ & & & $\mathbf{V}$ & \\
\hline 24 & $\begin{array}{c}\text { Papua New } \\
\text { Guinea }\end{array}$ & 1 & $1 / 2011-4 / 2012$ & 0.3 & 0.3 & & & & $\mathbf{V}$ & & & $\mathbf{v}$ & \\
\hline \multirow{2}{*}{25} & \multirow{2}{*}{ Philippines } & \multirow{2}{*}{2} & $6 / 2012-12 / 2014$ & 3.00 & 3.00 & $\sqrt{ }$ & & & $\mathbf{V}$ & & & & $\mathbf{v}$ \\
\hline & & & $12 / 2008-12 / 2010$ & 200 & 200 & $\mathbf{v}$ & $\sqrt{ }$ & $\boldsymbol{V}$ & $\sqrt{ }$ & & $\sqrt{ }$ & & \\
\hline \multirow{2}{*}{26} & \multirow{2}{*}{ Timor Leste } & \multirow{2}{*}{2} & $3 / 2010-6 / 2011$ & 0.07 & 0.07 & & & & & & & $\mathbf{V}$ & \\
\hline & & & Not effective & 2.0 & 2.0 & & & & $\mathbf{v}$ & & & $\mathbf{v}$ & \\
\hline
\end{tabular}




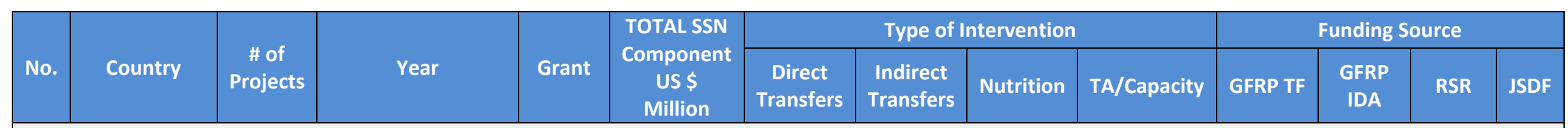

\section{Europe \& Central Asia}

\begin{tabular}{|c|c|c|c|c|c|c|c|c|c|c|c|c|}
\hline 27 & Albania & 1 & $12 / 2009-12 / 2010$ & 0.05 & 0.05 & & & $\mathbf{v}$ & & & $\boldsymbol{V}$ & \\
\hline \multirow{3}{*}{28} & \multirow{3}{*}{$\begin{array}{l}\text { Kyrgyz } \\
\text { Republic }\end{array}$} & \multirow{3}{*}{3} & $3 / 2010-6 / 2011$ & 0.05 & 0.05 & & & $\sqrt{ }$ & & & $\boldsymbol{V}$ & \\
\hline & & & $06 / 2008-N / A$ & 10 & 6 & $\sqrt{ }$ & $\sqrt{ }$ & $\mathbf{v}$ & & $\boldsymbol{v}$ & & \\
\hline & & & $07 / 2011-06 / 2012$ & 0.26 & 0.26 & & & $\sqrt{ }$ & & & $\sqrt{ }$ & \\
\hline 29 & Moldova & 1 & $08 / 2008-N / A$ & 7 & 7 & $\sqrt{ }$ & $\mathbf{v}$ & & $\sqrt{ }$ & & & \\
\hline \multirow{3}{*}{30} & \multirow{3}{*}{ Tajikistan } & \multirow{3}{*}{3} & $7 / 2010-6 / 2012$ & 2.55 & 2.55 & $\mathbf{v}$ & & $\sqrt{ }$ & & & $\mathbf{V}$ & \\
\hline & & & $6 / 2010-11 / 20014$ & 2.8 & 2.8 & & $\sqrt{ }$ & & & & & $\mathbf{v}$ \\
\hline & & & $06 / 2008-05 / 2013$ & 9 & 4 & & $\sqrt{ }$ & $\sqrt{ }$ & $\sqrt{ }$ & & & \\
\hline
\end{tabular}

\section{Middle East \& North Africa}

\begin{tabular}{|c|c|c|c|c|c|c|c|c|c|c|c|c|}
\hline \multirow{3}{*}{31} & \multirow{3}{*}{ Djibouti } & \multirow{3}{*}{3} & $6 / 2010-12 / 2014$ & 3.64 & 3.64 & & & $\mathbf{v}$ & & & & $\sqrt{ }$ \\
\hline & & & $1 / 2010-6 / 2011$ & 0.1 & 0.1 & & & & $\boldsymbol{V}$ & & $\boldsymbol{V}$ & \\
\hline & & & $05 / 2008-06 / 2009$ & 5 & 5 & & $\mathbf{v}$ & & $\mathbf{V}$ & $\boldsymbol{v}$ & & \\
\hline \multirow[b]{2}{*}{32} & \multirow{2}{*}{$\begin{array}{c}\text { West Bank \& } \\
\text { Gaza }\end{array}$} & \multirow[b]{2}{*}{2} & $11 / 2008-N / A$ & 3.4 & 3.4 & $\sqrt{ }$ & & & & $\mathbf{v}$ & & \\
\hline & & & $11 / 2008$ - N/A & 5 & 5 & $\mathbf{V}$ & & & & v & & \\
\hline \multirow{3}{*}{33} & \multirow{3}{*}{ Yemen } & \multirow{3}{*}{3} & 1/2011-6/2012 & 2 & 2 & $\sqrt{ }$ & & v & $\sqrt{ }$ & & $\sqrt{ }$ & \\
\hline & & & N/A & 25 & 25 & $\mathbf{v}$ & & & & $\sqrt{ }$ & & \\
\hline & & & $06 / 2008-12 / 2009$ & 10 & 10 & $\sqrt{ }$ & & & $\sqrt{ }$ & $\boldsymbol{V}$ & & \\
\hline
\end{tabular}




\begin{tabular}{|c|c|c|c|c|c|c|c|c|c|c|c|c|c|}
\hline \multirow[b]{2}{*}{ No. } & \multirow[b]{2}{*}{ Country } & \multirow[b]{2}{*}{$\begin{array}{l}\text { \# of } \\
\text { Projects }\end{array}$} & \multirow[b]{2}{*}{ Year } & \multirow[b]{2}{*}{ Grant } & \multirow{2}{*}{$\begin{array}{c}\text { TOTAL SSN } \\
\text { Component } \\
\text { US \$ } \\
\text { Million }\end{array}$} & \multicolumn{4}{|c|}{ Type of Intervention } & \multicolumn{4}{|c|}{ Funding Source } \\
\hline & & & & & & $\begin{array}{l}\text { Direct } \\
\text { Transfers }\end{array}$ & $\begin{array}{l}\text { Indirect } \\
\text { Transfers }\end{array}$ & Nutrition & TA/Capacity & GFRP TF & $\begin{array}{l}\text { GFRP } \\
\text { IDA }\end{array}$ & RSR & JSDF \\
\hline \multicolumn{14}{|c|}{ Latin America \& The Caribbean } \\
\hline \multirow{4}{*}{34} & \multirow{4}{*}{ Haiti } & \multirow{4}{*}{4} & $6 / 2010-3 / 2012$ & 2.84 & 2.84 & $\mathbf{v}$ & & & $\mathbf{v}$ & & & & $\mathbf{v}$ \\
\hline & & & $9 / 2010-9 / 2012$ & 3.0 & 3.0 & & & $\mathbf{v}$ & $\mathbf{v}$ & & & $\mathbf{v}$ & \\
\hline & & & $11 / 2010-6 / 2011$ & 0.07 & 0.07 & & & & 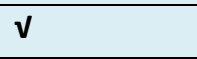 & & & $\sqrt{ }$ & \\
\hline & & & $05 / 2008-12 / 2008$ & 10 & 10 & $\mathbf{v}$ & $\mathbf{v}$ & & $\mathbf{v}$ & $\mathbf{v}$ & & & \\
\hline \multirow{2}{*}{35} & \multirow{2}{*}{ Honduras } & \multirow{2}{*}{2} & $11 / 2009-1 / 2011$ & 2.54 & 2.54 & $\mathbf{v}$ & & & & & & & $v$ \\
\hline & & & $1 / 2010-6 / 2011$ & 0.07 & 0.07 & & & & $\mathbf{v}$ & & & $\mathbf{v}$ & \\
\hline 36 & Jamaica & 1 & $7 / 2010-09 / 2013$ & 2.5 & 2.5 & $\mathbf{v}$ & & & $\mathbf{v}$ & & & & $\mathbf{v}$ \\
\hline \multirow{4}{*}{37} & \multirow{4}{*}{ Nicaragua } & \multirow{4}{*}{4} & $6 / 2010-7 / 2012$ & 2.9 & 2.9 & & & $\mathbf{v}$ & & & & & $v$ \\
\hline & & & $1 / 2011-9 / 2012$ & 0.2 & 0.2 & & & & $\sqrt{ }$ & & & $\sqrt{ }$ & \\
\hline & & & $1 / 2009-$ & 7.3 & 7.3 & & & $\mathbf{v}$ & & $\mathbf{v}$ & & & \\
\hline & & & $7 / 2011-9 / 2012$ & 2.75 & 2.3 & & & & & & & $\mathbf{v}$ & \\
\hline \multicolumn{14}{|c|}{ South Asia } \\
\hline \multirow{2}{*}{38} & \multirow{2}{*}{ Bangladesh } & \multirow{2}{*}{2} & $9 / 2010-12 / 2012$ & 2.9 & 2.9 & $\boldsymbol{v}$ & & & & & & $\mathbf{v}$ & \\
\hline & & & $7 / 2011-9 / 2012$ & 1 & 0.7 & & & & 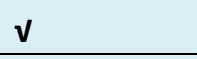 & & & $\sqrt{ }$ & \\
\hline \multirow{2}{*}{39} & \multirow{2}{*}{ India } & \multirow{2}{*}{2} & $3 / 2010-6 / 2011$ & 0.09 & 0.09 & & & & $\mathbf{v}$ & & & $\mathbf{v}$ & \\
\hline & & & $2 / 2010-7 / 2011$ & 0.1 & 0.1 & & & & $v$ & & & $\mathbf{v}$ & \\
\hline \multirow{2}{*}{40} & \multirow{2}{*}{ Maldives } & \multirow{2}{*}{2} & $1 / 2010-6 / 2011$ & 0.15 & 0.15 & & & & $v$ & & & $v$ & \\
\hline & & & $3 / 2011-9 / 2012$ & 0.1 & 0.1 & & & & $\mathbf{v}$ & & & $\sqrt{ }$ & \\
\hline \multirow{4}{*}{41} & & & Not effective & 2 & 2 & $\mathbf{v}$ & & & $\mathbf{v}$ & & & $\mathbf{v}$ & \\
\hline & & 1 & $5 / 2010$ & 47.8 & 41.8 & $v$ & & 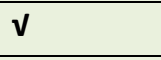 & $\mathbf{v}$ & & v & & \\
\hline & Nepal & 4 & $09 / 2008-08 / 2013$ & 5 & 5 & v & & $\mathbf{v}$ & $\mathbf{v}$ & $\mathbf{v}$ & & & \\
\hline & & & 09/2008-08/2013 & 31 & 16.7 & $\mathbf{v}$ & & $\mathbf{v}$ & & & $\mathbf{v}$ & & \\
\hline 2 & Cril onlo & 2 & $1 / 2011-1 / 2015$ & 2.73 & 2.73 & & & $\mathbf{v}$ & $\mathbf{v}$ & & & & v \\
\hline 42 & SrI Lanka & 2 & $6 / 2010-9 / 2012$ & 0.2 & 0.2 & & & & $\mathbf{v}$ & & & $\mathbf{v}$ & \\
\hline
\end{tabular}




\section{Social Protection Discussion Paper Series Titles}

No. $\quad \underline{\text { Title }}$

1118 Assessing Safety Net Readiness in Response to Food Price Volatility by Margaret Grosh, Colin Andrews, Rodrigo Quintana, Claudia Rodriguez-Alas, September 2011

1117 Social Safety Nets in Fragile States: A Community-Based School Feeding Program in Togo, August 2011 (also available in French)

1116 Strengthening Governance of Social Safety Nets in East Asia by Sara Giannozzi and Asmeen Khan, August 2011 (online only)

1115 International Portability of Health-Cost Coverage: Concepts and Experience by Martin Werding and Stuart McLennan, July 2011 (online only)

1114 Liberia’s Cash For Work Temporary Employment Project: Responding to Crisis in Low Income, Fragile Countries

by Colin Andrews, Prospère Backiny-Yetna, Emily Garin, Emily Weedon, Quentin Wodon and Giuseppe Zampaglione, July 2011

1113 Employability and Productivity among Older Workers: A Policy Framework and Evidence from Latin America

by Edmundo Murrugarra, July 2011 (online only)

1112 Cash Transfers, Children and the Crisis: Protecting Current and Future Investments

by Ariel Fiszbein, Dena Ringold, Santhosh Srinivasan, June 2011 (online only)

1111 Severance Pay Programs around the World: History, Rationale, Status, and Reforms

by Robert Holzmann, Yann Pouget, Milan Vodopivec and Michael Weber, May 2011 (online only)

1110 Portability of Pension, Health, and other Social Benefits: Facts, Concepts, Issues by Robert Holzmann and Johannes Koettl, May 2011 (online only)

1109 Disability and Poverty in Developing Countries: A Snapshot from the World Health Survey by Sophie Mitra, Aleksandra Posarac and Brandon Vick, April 2011

1108 Advancing Adult Learning in Eastern Europe and Central Asia by Christian Bodewig and Sarojini Hirshleifer, April 2011 (online only)

1107 Results Readiness in Social Protection \& Labor Operations by Laura Rawlings, Maddalena Honorati, Gloria Rubio and Julie Van Domelen, February 2011 
1106 Results Readiness in Social Protection \& Labor Operations: Technical Guidance Notes for Social Service Delivery Projects

by Julie Van Domelen, February 2011

1105 Results Readiness in Social Protection \& Labor Operations: Technical Guidance Notes for Social Safety Nets Task Teams

by Gloria Rubio, February 2011

1104 Results Readiness in Social Protection \& Labor Operations: Technical Guidance Notes for Social Funds Task Teams

by Julie Van Domelen, February 2011

1103 Results Readiness in Social Protection \& Labor Operations: Technical Guidance Notes for Labor Markets Task Teams

by Maddalena Honorati, February 2011

1102 Natural Disasters: What is the Role for Social Safety Nets?

by Larissa Pelham, Edward Clay and Tim Braunholz, February 2011

1101 North-South Knowledge Sharing on Incentive-based Conditional Cash Transfer Programs

by Lawrence Aber and Laura B. Rawlings, January 2011

1008 Social Policy, Perceptions and the Press: An Analysis of the Media’s Treatment of Conditional Cash Transfers in Brazil

by Kathy Lindert and Vanina Vincensini, December 2010 (online only)

1007 Bringing Financial Literacy and Education to Low and Middle Income Countries: The Need to Review, Adjust, and Extend Current Wisdom by Robert Holzmann, July 2010 (online only)

1006 Key Characteristics of Employment Regulation in the Middle East and North Africa

by Diego F. Angel-Urdinola and Arvo Kuddo with support from Kimie Tanabe and May Wazzan, July 2010 (online only)

1005 Non-Public Provision of Active Labor Market Programs in Arab-Mediterranean Countries: An Inventory of Youth Programs

by Diego F. Angel-Urdinola, Amina Semlali and Stefanie Brodmann, July 2010 (online only)

1004 The Investment in Job Training: Why Are SMEs Lagging So Much Behind? by Rita K. Almeida and Reyes Aterido, May 2010 (online only)

1003 Disability and International Cooperation and Development: A Review of Policies and Practices

by Janet Lord, Aleksandra Posarac, Marco Nicoli, Karen Peffley, Charlotte McClain-Nhlapo and Mary Keogh, May 2010

1002 Toolkit on Tackling Error, Fraud and Corruption in Social Protection Programs by Christian van Stolk and Emil D. Tesliuc, March 2010 (online only) 
1001 Labor Market Policy Research for Developing Countries: Recent Examples from the Literature - What do We Know and What should We Know?

by Maria Laura Sanchez Puerta, January 2010 (online only)

0931 The Korean Case Study: Past Experience and New Trends in Training Policies by Young-Sun Ra and Kyung Woo Shim, December 2009 (online only)

0930 Migration Pressures and Immigration Policies: New Evidence on the Selection of Migrants

by Johanna Avato, December 2009 (online only)

0929 Ex-Ante Methods to Assess the Impact of Social Insurance Policies on Labor Supply with an Application to Brazil

by David A. Robalino, Eduardo Zylberstajn, Helio Zylberstajn and

Luis Eduardo Afonso, December 2009 (online only)

$0928 \quad$ Rethinking Survivor Benefits

by Estelle James, December 2009 (online only)

0927 How Much Do Latin American Pension Programs Promise to Pay Back? by Alvaro Forteza and Guzmán Ourens, December 2009 (online only)

0926 Work Histories and Pension Entitlements in Argentina, Chile and Uruguay by Alvaro Forteza, Ignacio Apella, Eduardo Fajnzylber, Carlos Grushka, Ianina Rossi and Graciela Sanroman, December 2009 (online only)

$0925 \quad$ Indexing Pensions

by John Piggott and Renuka Sane, December 2009 (online only)

$0924 \quad$ Towards Comprehensive Training by Jean Fares and Olga Susana Puerto, November 2009

0923 Pre-Employment Skills Development Strategies in the OECD by Yoo Jeung Joy Nam, November 2009

0922 A Review of National Training Funds by Richard Johanson, November 2009

0921 Pre-Employment Vocational Education and Training in Korea by ChangKyun Chae and Jaeho Chung, November 2009

0920 Labor Laws in Eastern European and Central Asian Countries: Minimum Norms and Practices by Arvo Kuddo, November 2009 (online only)

0919 Openness and Technological Innovation in East Asia: Have They Increased the Demand for Skills?

by Rita K. Almeida, October 2009 (online only) 
0918 Employment Services and Active Labor Market Programs in Eastern European and Central Asian Countries by Arvo Kuddo, October 2009 (online only)

0917 Productivity Increases in SMEs: With Special Emphasis on In-Service Training of Workers in Korea

by Kye Woo Lee, October 2009 (online only)

0916 Firing Cost and Firm Size: A Study of Sri Lanka's Severance Pay System

by Babatunde Abidoye, Peter F. Orazem and Milan Vodopivec, September 2009 (online only)

0915 Personal Opinions about the Social Security System and Informal Employment: Evidence from Bulgaria

by Valeria Perotti and Maria Laura Sánchez Puerta, September 2009

0914 Building a Targeting System for Bangladesh based on Proxy Means Testing by Iffath A. Sharif, August 2009 (online only)

0913 Savings for Unemployment in Good or Bad Times: Options for Developing Countries

by David Robalino, Milan Vodopivec and András Bodor, August 2009 (online only)

0912 Social Protection for Migrants from the Pacific Islands in Australia and New Zealand

by Geoff Woolford, May 2009 (online only)

0911 Human Trafficking, Modern Day Slavery, and Economic Exploitation by Johannes Koettl, May 2009

0910 Unemployment Insurance Savings Accounts in Latin America: Overview and Assessment

by Ana M. Ferrer and W. Craig Riddell, June 2009 (online only)

0909 Definitions, Good Practices, and Global Estimates on the Status of Social Protection for International Migrants

by Johanna Avato, Johannes Koettl, and Rachel Sabates-Wheeler, May 2009 (online only)

0908 Regional Overview of Social Protection for Non-Citizens in the Southern African Development Community (SADC) by Marius Olivier, May 2009 (online only)

0907 Introducing Unemployment Insurance to Developing Countries by Milan Vodopivec, May 2009 (online only)

0906 Social Protection for Refugees and Asylum Seekers in the Southern Africa Development Community (SADC) by Mpho Makhema, April 2009 (online only) 
0905 How to Make Public Works Work: A Review of the Experiences

by Carlo del Ninno, Kalanidhi Subbarao and Annamaria Milazzo, May 2009

(online only)

0904 Slavery and Human Trafficking: International Law and the Role of the World Bank

by María Fernanda Perez Solla, April 2009 (online only)

0903 Pension Systems for the Informal Sector in Asia

edited by Landis MacKellar, March 2009 (online only)

0902 Structural Educational Reform: Evidence from a Teacher's Displacement Program in Armenia

by Arvo Kuddo, January 2009 (online only)

$0901 \quad$ Non-performance of the Severance Pay Program in Slovenia

by Milan Vodopivec, Lilijana Madzar, Primož Dolenc, January 2009 (online only)

To view Social Protection Discussion papers published prior to 2009, please visit www.worldbank.org/sp. 


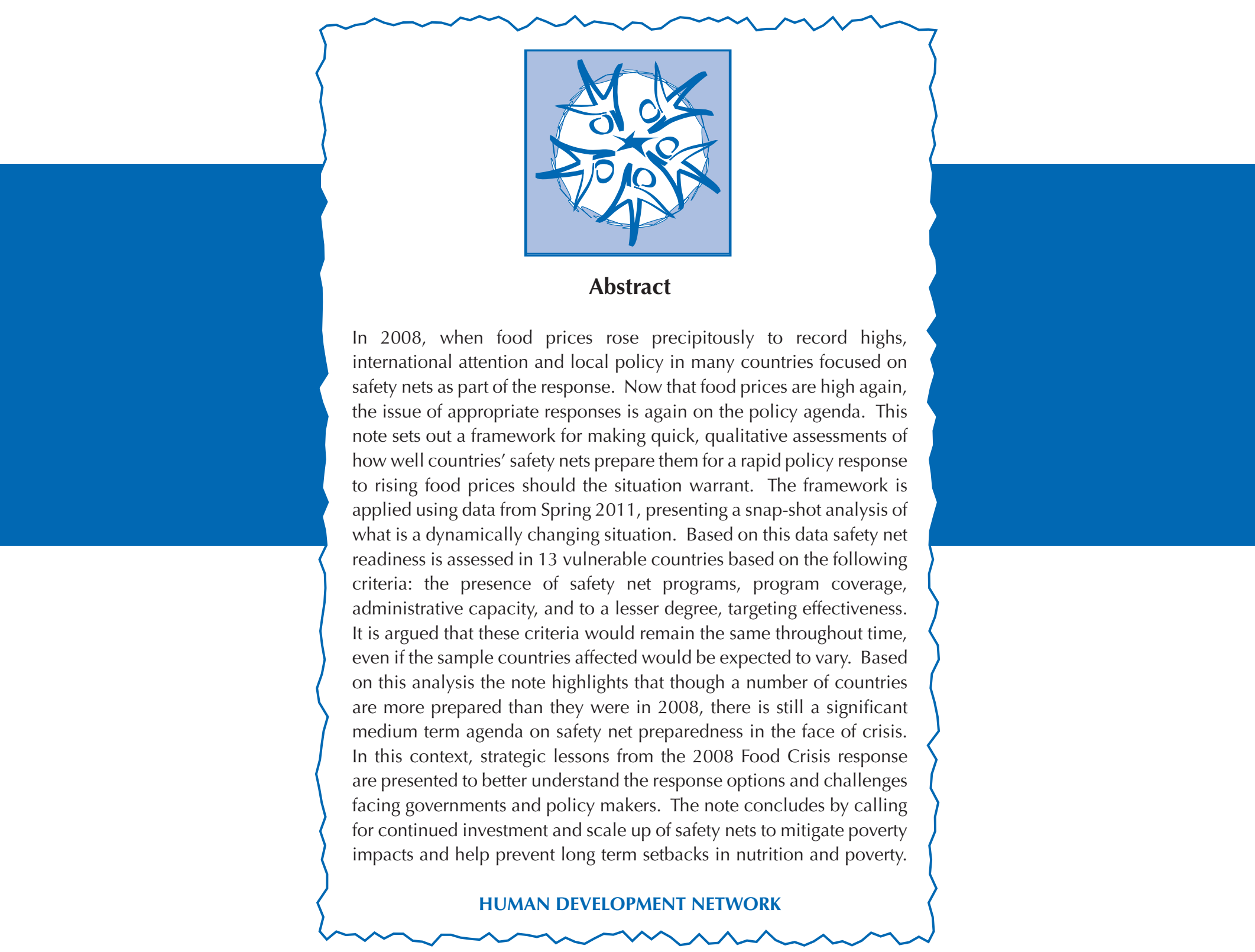

